IZA DP No. 9680

Paying to Avoid Recession:

Using Reenlistment to Estimate the Cost of Unemployment

Mark Borgschulte

Paco Martorell

January 2016 


\title{
Paying to Avoid Recession: Using Reenlistment to Estimate the Cost of Unemployment
}

\author{
Mark Borgschulte \\ University of Illinois at Urbana-Champaign \\ and IZA \\ Paco Martorell \\ University of California at Davis \\ Discussion Paper No. 9680 \\ January 2016 \\ IZA \\ P.O. Box 7240 \\ 53072 Bonn \\ Germany \\ Phone: +49-228-3894-0 \\ Fax: +49-228-3894-180 \\ E-mail: iza@iza.org
}

Any opinions expressed here are those of the author(s) and not those of IZA. Research published in this series may include views on policy, but the institute itself takes no institutional policy positions. The IZA research network is committed to the IZA Guiding Principles of Research Integrity.

The Institute for the Study of Labor (IZA) in Bonn is a local and virtual international research center and a place of communication between science, politics and business. IZA is an independent nonprofit organization supported by Deutsche Post Foundation. The center is associated with the University of Bonn and offers a stimulating research environment through its international network, workshops and conferences, data service, project support, research visits and doctoral program. IZA engages in (i) original and internationally competitive research in all fields of labor economics, (ii) development of policy concepts, and (iii) dissemination of research results and concepts to the interested public.

IZA Discussion Papers often represent preliminary work and are circulated to encourage discussion. Citation of such a paper should account for its provisional character. A revised version may be available directly from the author. 


\section{ABSTRACT \\ Paying to Avoid Recession: Using Reenlistment to Estimate the Cost of Unemployment ${ }^{*}$}

This paper provides revealed-preference estimates of the monetary value of avoiding job search in a high-unemployment labor market by examining the behavior of military servicemembers deciding between reenlisting and exiting the military. We find that servicemembers would sacrifice $1.5-2 \%$ in earnings in exchange for avoiding a one percentage point increase in the home-state unemployment rate. Comparing these estimates to realized losses in post-service civilian earnings resulting from exiting the military during times of high unemployment suggests that mitigating factors (e.g., leisure, private and public transfers) offset less than one-third of the earnings losses caused by entering a weak labor market.

JEL Classification: J30, J60, J65

Keywords: welfare cost of business cycles, labor market entry, military reenlistment

Corresponding author:

Mark Borgschulte

Department of Economics

University of Illinois, Urbana-Champaign

1407 W Gregory Drive

Urbana, IL 61801

USA

E-mail: markborg@illinois.edu

\footnotetext{
* For comments and other assistance, we thank Beth Asch, Matt Botsch, David Card, Flavio Cunha, Jason Faberman, Eliza Forsythe, François Gerard, Jim Hosek, Pat Kline, Ron Lee, Dave Loughran, Vikram Maheshri, Ulrike Malmendier, Pascal Michaillat, Maury Obstfeld, Carl Nadler, Issi Romem, Jesse Rothstein, Emmanuel Saez, David Silver, Lanwei Yang, and seminar participants at UC Berkeley, Chicago Federal Reserve, United States Military Academy, University of Miami, University of Virginia, University of Illinois at Urbana-Champaign, University of Illinois at Chicago, Society of Labor Economists Meetings, Southern Economics Association Meetings, San Francisco State, Census Bureau and RAND.
} 
Recent research establishes that business cycle conditions at the time of job search exert a large and persistent effect on the subsequent earnings and occupations of displaced workers and new college graduates.$^{1}$ However, the welfare costs to these labor market transitions could be offset by increased leisure, public and private transfers, and other mechanisms. How much would workers be willing to pay to avoid these earnings losses therefore remains unclear, with the value of social insurance programs, job creation, and stabilization policy depending crucially on the answer to this question.

Existing empirical evidence on the welfare costs of business cycles and how earnings losses in recessions translate into welfare losses is mixed, supporting a wide range of offsets. Evidence that focuses on the long-run outcomes, health and subjective well-being of displaced workers and labor market entrants suggests large costs to business cycle fluctuations. ${ }^{2}$ On the other hand, the relatively weak response of consumption to job loss has been interpreted as evidence against it having large welfare costs $3^{3}$ Similarly, calibrated search models require small welfare costs to job destruction to match the weak cyclical response of real wages relative to unemployment. ${ }^{4}$

In this paper we present new revealed-preference estimates of the monetary value of avoiding a high-unemployment labor market, based on the direct observation of reenlistment choices of military servicemembers. The underlying idea is simple: if labor market conditions affect not only earnings, but also welfare, people will be willing to pay more to enter the labor market when unemployment is low. In the case of the reenlistment decision, the costly option takes the form of giving up the (often generous) reenlistment bonuses that are used by the military to balance the supply and demand for different occupation groups. We fit reenlistment choice models that include the value of the reenlistment bonus offered to each person, as well as the unemployment rate in their home state (i.e., the state of residence just prior to joining the military). These models provide estimates of the willingness to pay to avoid a higher unemployment rate, a sufficient statistic for the total response of all economic and psychological costs associated with job search at different

\footnotetext{
${ }^{1}$ See Genda et al. (2010), Kahn (2010) and Oreopoulos et al. (2012) for earnings effects among college graduates, Jacobson et al. (1993) and Davis et al. (2011) for effects among displaced US workers, and Altonji et al. (2016) for evidence on occupation.

${ }^{2}$ For example, see for subjective well-being: Clark and Oswald (1994), Wolfers (2003), Blanchflower and Oswald (2004), Di Tella et al. (2003), Di Tella et al. (2010), Deaton (2012), Helliwell and Huang (2014); health: Sullivan and von Wachter (2009), Schaller and Stevens (2015).

${ }^{3}$ Examples of consumption-based welfare estimates include Cochrane (1991), Gruber (1997), and Blundell et al. (2008). Interpretation of consumption responses is complicated by consumption commitments (Chetty and Szeidl 2007), household responses (Blundell et al. 2015), and household heterogeneity (as inin Krebs (2007) and Krusell et al. (2009) Schulhofer-Wohl (2011)).

${ }^{4}$ For example, Shimer 2005 and Hagedorn and Manovskii 2008. Intuitively, if job losers faced large welfare costs, firms could respond to demand shocks through lower wages rather than layoffs. See Shimer and Rogerson 2011 for an overview.
} 
points in the business cycle. $5^{5}$ We then directly estimate the effect of the home-state unemployment rate using administrative data on the earnings of individuals who leave the military and enter the civilian labor market. We then compare the willingness to pay to avoid higher unemployment with the earnings losses generated by entering the labor market in periods of high unemployment to calculate the fraction of the earnings loss offset by mitigating factors such as public transfers.

The military setting permits us the rare opportunity to observe workers' decisions to exit employment at independent levels of the wage and unemployment rate. Four key features of the military reenlistment setting and the available data are critical to our approach. First, the military recruits workers from all 50 states, but sets a national compensation policy. Thus, we can compare workers facing similar contract offers to stay in the military but subject to distinct, exogenous shocks to their home labor markets. Second, the bonuses used by the military to control occupation-specific reenlistment flows are set based on observable characteristics, allowing us to recover contract offers that were not consummated. Although there is an individual-specific component in the actual received bonuses, we can use average bonuses paid to an occupation group or other system-level measures of occupation-specific demand to address this source of endogeneity. Third, reenlistment entails a significant commitment-usually a minimum of 3 or 4 additional years-forcing a discrete decision over the value of employment. A fourth key feature regards the size of the military and the availability of detailed administrative data. The military is a very large national employer (over 1.1 million enlisted servicemembers at any time, with approximately 180,000 new enlistees each year and an equal number of people leaving the service). Our data permits us to observe the contracts, military pay, and characteristics of enlisted servicemembers for a large number of cohorts (1993-2009) as well as Social Security Administration (SSA) earnings records on post-service earnings for those who leave the military, and Veterans Administration records on college benefit (GI Bill) usage.

We begin our empirical analysis by estimating choice models that include the reenlistment bonus and the home-state unemployment rate, as well as a rich set of controls, including AFQT, for the characteristics of the service member and his occupation. We find that reenlistment rates are highly responsive to both retention bonuses and the home-state unemployment rate. Our implied elasticities of the reenlistment rate with respect to bonuses are in the range of 1 to 1.5 , similar to the range in the existing literature. The ratio of the estimated effect of the home-state unemployment rate to the effect of the bonus-which roughly equates to the increase in the wage over the next contract required to generate the same reenlistment response as a one point increase in home-state unemployment rate-imply that young veterans are willing to trade no less than $1 \%$, and as much

\footnotetext{
${ }^{5}$ See Chetty $[2009)$.
} 
as $2.4 \%$ of their military wage to avoid a 1-point increase in the home-state unemployment rate at exit. Since half of the bonus is paid on signing, discounting will increase the value of the bonus payments relative to this baseline.

We then connect the estimated willingness-to-pay to observed earnings losses. To do so, we follow previous studies of job search over the business cycle and estimate of the effect of the local (i.e., home state) unemployment at the time of leaving the military on subsequent SSA earnings outcomes. Consistent with evidence on displaced workers and labor market entrants, we find that people who leave the military when their home-state unemployment rate is higher suffer large and persistent earnings losses over the next decade. In their first full year out of the military, young veterans who complete their term of service between 1993 and 2009 could expect to lose $3.6 \%$ of their annual earnings for each 1 percentage point increase in their home-state unemployment rate, with effects statistically distinguishable from zero for 7 years. A concern with these estimates is that there may be selectivity biases in the characteristics of veterans who choose to leave the military when their home-state unemployment rate is higher or lower. We use the bonus offers to each individual's occupation in the year of their reenlistment decision to develop a control function for the degree of selection bias. The corrected estimates are quite similar to our baseline estimates, suggesting that selection biases in our context are small. These estimates are notably larger than the estimates reported by Oreopoulos et al.(2012) for new college graduates in Canada, potentially reflecting the greater cyclicality of wages for high-school educated workers than college educated workers. ${ }^{6}$ Part of the difference may also reflect the inclusion of the Great Recession in our study period: when we disaggregate our results by time period, we find that the effects of the home-state unemployment rate are amplified in recessions, and are particularly large in the 2007-2009 period.

We then asses the extent to which earnings losses resulting from job search during times of high unemployment generate welfare losses by comparing the estimated willingness to pay to avoid a higher home-state unemployment rate with the estimated earnings losses experienced by military leavers who are exposed to different home-state labor markets. In our preferred estimates, earnings losses are not much larger than the willingness to pay, and we estimate that mitigating mechanisms like public and private transfers and leisure offset 13 to $35 \%$ of the realized earnings losses. Discounting these losses at rates estimated in the previous literature suggests a percentage point of home-state unemployment at the time of separation from the military results in the loss of approximately $1.31 \%$ of lifetime earnings, and $1 \%$ of lifetime utility; accounting for endogenous migration, the timing of the decision and separation from the military would increase these

\footnotetext{
${ }^{6}$ See Hoynes et al. (2012) for evidence and citations to the literature on the income and demographic gradients in exposure to business cycles.
} 
earnings and utility losses by an additional 30\%. We suspect that the offset effect we estimate for young veterans to be an overestimate of the degree of offset for other similar workers, as US veterans anticipate this transition, and have access to a range of targeted public programs, including generous education/job-training benefits and unemployment insurance.

\section{Reenlistment of Enlisted Men and Sample Characteristics}

As with displaced workers and college graduates, young veterans of the US military have limited control over the timing of job search. This occurs due to fixed-length enlistment contract and limited opportunities to voluntarily leave the military before the expiration of the contract. Around $60 \%$ of enlisted servicemembers exit service at the end of the first contract, totaling over 100,000 people per year. To put this in context, this equates to 6-7\% of the flow of new college graduates in the United States.

Enlisted servicemembers in the Army, Navy, Marines and Air Force sign similar contracts at entry, and face common institutional features in their reenlistment choice. These servicemembers enter the military having selected a branch of service, term of service and occupational specialization. As the end of the initial enlistment contract nears, servicemembers in all four branches enter a reenlistment window, during which they face a menu of options over the term, occupation and duty assignment in their new contract. The military uses Special Reenlistment Bonuses (SRB) as the primary tool to control reenlistment and incentivize movement into under-staffed occupations. The SRB pays the product of an occupation-specific multiplier, the servicemembers' base pay and the additional years of service commitment, up to a maximum of $\$ 100,000$. Given their importance to the supply of military manpower, the SRB program is the focus of a number of economic analyses of reenlistment incentives. ${ }^{7}$ Half of the bonus is paid within a month of reenlistment, and the other half is paid over the course of the new contract $]^{8}$ We refer to effects of the payment schedule as the cash-in-hand component of the bonus.

Military labor demand and bonus setting reflect several considerations. The Department of Defense sets enlistment and reenlistment targets, reflecting projected deployment needs, military doctrine and Congressionally-authorized funding levels. Bonuses are then set to clear the market, with updates occurring as often as several days apart. In addition to controlling occupation-specific reenlistment flows, bonuses may also serve to offset relative changes in working conditions be-

\footnotetext{
${ }^{7}$ For example, Hosek and Martorell (2009), Asch et al. (2010) and Greenstone et al. (2014) analyze SRB bonuses. See Hosek and Martorell (2009) and Asch et al. (2010)) for a detailed discussion of SRB bonuses.

${ }^{8}$ The Marine Corps, the smallest service branch, switched to a lump-sum bonus in 2001. The switch to a lump-sum bonus will bias our estimates towards a smaller willingness to pay.
} 
tween military and civilian life. Average bonuses increase during overseas conflicts necessitating deployments and increased mortality risk, as well as civilian labor market booms. In the time series, reported in Appendix Figure A1, only $40 \%$ of reenlistment contracts included a bonus during the drawdown of the mid-1990s, while this increased to $80 \%$ at the height of the Iraq and Afghanistan wars. As well, bonuses increased during the robust economy of the late 1990s, and then again during the wars. During peacetime, cross-occupation variation in demand and bonuses primarily arises due to changes in military doctrine and to maintain a relatively constant tenure pyramid within occupation; during wartime, those occupations with the highest mortality risk will require additional compensation. The military may also delay separation using "stop-loss" provisions, which extend the contract term through the end of a servicemember's deployment.

Should servicemembers choose to exit the military (i.e. not reenlist), they are discharged at or near the end of their current contract. Early separation may be negotiable in the final months of the contract, depending on the needs of the military. Upon entering civilian life, veterans become eligible for GI Bill college and training benefits, disability and a limited set of means-tested benefits, such as health care, and a range of state-level programs, such as unemployment insurance, preferential hiring and housing assistance.

\subsection{Data and Sample Characteristics}

We use military administrative data encompassing the universe of enlisted military personnel who served on active duty between 1988 and 2010, linked to their SSA earnings files through 2010 and college benefit usage through mid-2009. Administrative pay records decompose income into categories that include the total value of bonus payments, which we use to recover average bonus offers made in each occupation. The pay records also contain information on in-service experience shown to affect reenlistment, such as receipt of deployment pay, hostile fire pay and stop-loss.

In order to harness the largest possible group of servicemembers subject to standardized contracts, we study the population of enlisted, active-duty, first-term, male servicemembers from the four largest branches of the military, the Army, Navy, Marines and Air Force. We drop female servicemembers from the sample, a sample restriction that is consistent with previous literature on labor market entry and displaced workers 9 As well, we drop servicemembers who are discharged

\footnotetext{
${ }^{9}$ For example, see Oreopoulos et al. (2012), Kahn (2010) and Davis et al. (2011). Our preliminary analysis revealed that the earnings responses of young female veterans differ from the patterns of young male veterans, temporarily rising in response to unemployment at exit, a result consistent with an important fraction of women acting as secondary earners in their household. The analysis relies on (residualized) earnings cells from SSA, which must contain a minimum number of observations. Earnings results for women were also much noisier than the results for men, probably due to missing data. Given the data access constraints, we cannot analyze heterogenous earnings effects by gender, race/ethnicity or for some other subgroups.
} 
before the completion of the first year of their contract, because most of these discharges occur involuntarily, e.g. failing to meet standards during basic training. Attrition before the final quarter of the contract is not predicted by state unemployment-rate movements. Together, we have just under 1.1 million people in our sample. In our reenlistment analysis, missing data and the construction of the bonus variable will result in a different sample size across specifications; we discuss several robustness checks below, but have not found important patterns or biases resulting from the dropped observations.

We report our results for two groups: contracts ending between 1993 and 2004 (the primary sample), and those ending between 1993 and 2009 (the full sample). The 1993-2004 cohorts offer a number of advantages in analyzing both reenlistment and earnings outcomes. We list these here, beginning with the advantages in the reenlistment analysis. Of chief importance, the primary sample period offers the strongest support for our assumption of a stable military labor demand function. Although the final 3 years include the first years of the Global War on Terror, the Iraq and Afghanistan Wars had not yet devolved into protracted conflicts during these years. As a result, the military was broadly successful in meeting enlistment and reenlistment goals for first-term recruits during the 1993-2004 period, as opposed to the 2005-2007 period, in which the strain of the Iraq and Afghanistan conflicts led to large-scale shortfalls in enlistment and reenlistment. The 1993-2004 reenlistment cohorts originally joined the military during peacetime and before attacks of September 11, 2001, reducing concerns about selection into the military. We begin the analysis with the 1993 reenlistment cohort, as this is the first for which our data contains information on the full course of the initial contract for the entire finishing cohort (initial contracts for enlisted servicemembers are 6 years or shorter), allowing us to test for attrition and control for initial cohort size and bonuses. For earnings outcomes, the 1993-2009 cohorts form an unbalanced panel, and as we will see, the Great Recession may alter the experience-profile of losses. Thus, when we examine dynamics, we drop the final five cohorts for this portion of the analysis. The 1993-2004 cohort sample allows us to observe six years of post-service outcomes for those who separate at the end of the first contract, including behavior at the end of the second contract for those who reenlist and college benefit usage for those who exit. Additionally, data on the Montgomery GI Bill allows us to stratify earnings results by college benefit usage through 2004. In sum, the shorter sample period offers a number of analytical advantages in our subsequent analysis, though we extend the analysis through the Great Recession-era where appropriate.

The descriptive statistics in Table A1 show first-term enlisted men to be a young, diverse group of workers. Most enlisted men reach the end of their first contract between ages 22 and 27, with the average at 24. A large majority of this population enters the military unmarried, with their 
highest education being a high school diploma or equivalent. Although less than $10 \%$ enroll in college before entering the military, enlisted men are of slightly above average intelligence, as can be seen from the mean and percentiles for AFQT (the percentiles of which are normed to the US population). Looking at the AFQT percentiles, we can see the effect of entry standards on the lower tail is considerably stronger than selection effects at the top of the distribution. Thus, enlisted men are less-skilled than college graduates, but not than the general population. Enlisted men are also broadly representative of the racial/ethnic demographics of the US over this period; whites and blacks are slightly overrepresented, while Hispanics are slightly underrepresented. The restriction to the earlier sub-period has no important effects on the sample characteristics.

\section{Reenlistment Responses}

\subsection{Modeling Returns to Reenlistment and Labor Market Entry}

Our model summarizes the monetary value of exiting employment and entering job search over the course of the business cycle.

The servicemember faces a binary decision to reenlist by the end of the first contract or exit the military. Should he exit at the end of their contract, he receives a payoff, which we summarize with the value function for individual $i$, in occupation $o$, from state $s$, eligible for discharge in year $t$ :

$$
V_{i o s t}^{\text {exit }}=\alpha^{\text {exit }}+\beta U R_{s t}+\eta^{\text {exit }} \mathbf{X}_{\text {iost }}+\varepsilon_{\text {iost }}^{\text {exit }}
$$

where $\alpha^{\text {exit }}$ represents the average utility of exit, $\beta$ is the influence of the state unemployment on future utility, including both earnings losses and mitigating mechanisms like leisure and public and private transfers, and $\varepsilon_{\text {iost }}^{\text {exit }}$ is a time-varying shock to the utility of exit, representing idiosyncratic elements, such as a new job offer or the start of a romantic relationship. The primary coefficient of interest is $\beta$, the effect of a one percentage point change in home state unemployment rate, $U R_{s t}{ }^{10}$ The vector of controls, $\mathbf{X}_{\text {iost }}$, contains variables which influence the average value of exit, including state, year and occupation fixed effects, quadratic interactions of age with a rich set of demographic, health and education controls, such as AFQT, education at entry, marital status, height, weight, and race/ethnicity. We take this linear representation as an approximation of the total discounted value of exit 11

\footnotetext{
${ }^{10}$ In a slight abuse of notation, we use the unemployment rate in the three months following discharge eligibility in $U R_{s t}$.

${ }^{11}$ The linear model summarizes the data quite well, and perhaps surprisingly, the results in both the reenlistment
} 
If he reenlists, the servicemember receives a similar payoff:

$$
V_{i o s t}^{\text {reenlist }}=\alpha^{\text {reenlist }}+\gamma B_{\text {iot }}+\eta^{\text {reenlist }} \mathbf{X}_{\text {iost }}+\mu_{\text {iot }}+\varepsilon_{i o s t}^{\text {reenlist }} .
$$

In this equation, $\alpha^{\text {reenlist }}$ represents the average utility of reenlistment, $\gamma$ is the effect of a percent change in the pay operating through the bonus, $\mu_{i o t}$ is the taste for military service, and $\varepsilon_{\text {iost }}^{\text {reenlist }}$ represents idiosyncratic elements of the returns to reenlistment, for example, a particularly desirable posting. We think of $\mu_{i o t}=\mu_{i}+\mu_{o t}$, so that we can decompose the taste for service into the individual's time-invariant taste for service (for example, the effect of having a parent who served), and a time-varying component that we refer to as working conditions. 12

The response to the bonus in Equation 2, $\gamma$, will allow us to monetize the value of reenlistment. We convert the announced SRB multiplier to the implied percentage increase in the annual wage, $B_{i o t}$, as if the bonus were paid through increased earnings over the course of the next contract. We use this transformation in order to compare servicemembers with different levels of base pay. This modification will understate the value of the bonus for two reasons: first, the bonus carries with it an increase in the option value to reenlist at later reenlistment decisions, as there is serial correlation in bonus offers across contracts; and second, the cash-in-hand component of bonuses will lead to a higher value for the bonus (relative to an increase in pay over the course of the next contract) if discount rates exceed the growth rate of earnings $s^{13}$. Both of these factors will increase the value of the bonus, relative to the hypothetical increase in pay over the course of the next contract. In Section 4 we calibrate our willingness to pay elements to address these issues.

The servicemember chooses to reenlist if $V_{\text {iost }}^{\text {reenlist }}>V_{\text {iost }}^{\text {exit }}$. Combining these elements, the probability of individual $i$ reenlisting, denoted by the dummy variable $D_{\text {iost }}=1$, is:

$$
\begin{aligned}
\mathbb{P}\left[D_{\text {iost }}=1\right]=\mathbb{P}\left[V_{\text {iost }}^{\text {reenst }}>V_{\text {iost }}^{\text {exit }}\right] & \\
= & \mathbb{P}\left[\alpha^{\text {reenlist }}+\gamma B_{\text {iot }}+\mu_{\text {iot }}+\eta^{\text {reenlist }} \mathbf{X}_{\text {iost }}+\varepsilon_{\text {iost }}^{\text {reenlist }}\right. \\
& \left.\quad>\alpha^{\text {exit }}+\beta U R_{s t}+\eta^{\text {exit }} \mathbf{X}_{\text {iost }}+\varepsilon_{\text {iost }}^{\text {exit }}\right] \\
= & \mathbb{P}\left[\alpha-\beta U R_{s t}+\gamma B_{\text {iot }}+\mu_{\text {iot }}+\eta \mathbf{X}_{\text {iost }}>\varepsilon_{\text {iost }}^{\text {exit }}-\varepsilon_{\text {iost }}^{\text {reenlist }}\right] .
\end{aligned}
$$

Here, $\alpha \equiv \alpha^{\text {reenlist }}-\alpha^{\text {exit }}$ and $\eta \equiv \eta^{\text {reenlist }}-\eta^{\text {exit }}$. In Equation 3 , a point of unemployment increases the probability of reenlistment by $\beta$, while a $1 \%$ increase in the pay through the bonus increases

or earnings analysis are robust to their inclusion. As we lack the power to distinguish the effect of higher-order terms from zero, we did not include them in the final analysis.

${ }^{12}$ Although we did not enter a time-varying occupation-specific component in the returns to exit, they will be captured in $\mu_{o t}$ when we difference the two value functions.

${ }^{13}$ This is likely the case, given the high discount rates estimated in Warner and Pleeter (2001) 
the probability of reenlistment by $\gamma$. Dividing $\gamma$ by the average reenlistment rate (around $40 \%$ in our sample) will yield a reenlistment elasticity, which we can compare to previous estimates in the literature. We want to know how large of a bonus change, $\Delta B_{i o t}^{*}$, would be required to offset (i.e. hold constant the reenlistment rate in the presence of) a one point change in unemployment, $\gamma \Delta B_{i o t}^{*}=\beta * 1$, so $\Delta B_{i o t}^{*}=\beta / \gamma$. Given the discussion in the previous paragraph, we can interpret the ratio $\beta / \gamma$ as roughly the percentage change in earnings on the next contract that would compensate for a percentage point decrease in the unemployment rate. Multiplying the ratio by the monetary value of a bonus point returns our estimate of the willingness-to-pay to avoid unemployment at exit in Section 4

\subsection{Reenlistment Estimation}

The main analysis of reenlistment responses estimates Equation 2 using linear probability models. Figure 1 graphically depicts the analysis. In the model, the response to state unemployment $\beta$ reflects the avoidance of a worsening outside labor market and the response to bonus pay $\gamma$ allows us to price this avoidance behavior. Of the two, there is considerably more uncertainty in the estimation of $\gamma$. In most of the analysis, we average the bonus offers within career-field cohorts (2-digit occupation) to remove the individual-level variation in the bonus, and analyze variation in $B_{o t}$. The 2-digit occupation corresponds to a military "career field." In general, this is the broadest category of related occupations, and most occupation-switching at reenlistment occurs within these fields (an Appendix table provides examples).

To estimate the bonus response, we pursue the strategy used in recent military manpower studies (such as Hosek and Martorell (2009) and Asch et al. (2010)) 14 Research using wartime samples has primarily focused on the effect of unobserved working conditions on the bonus. These researchers have naturally been concerned that the response to increases in the bonus may understate the true effect of pay incentives, due to the negative correlation in $B_{o t}$ and $\mu_{o t}$. We minimize this concern by focusing the primary analysis on the 1993-2004 period, before the descent of the Afghanistan and Iraq Wars into protracted conflicts. To address this concern further, we add variables that proxy for working conditions-deployment history, receipt of hostile fire pay and measures of advancement in rank. ${ }^{15}$ Although we find no evidence of a significant bias in these estimates, we also investigated an instrumental variables model, based on the flow of new recruits

\footnotetext{
${ }^{14}$ Figure 1 summarizes the analysis in a binned scatter plot and the bonus in levels.

${ }^{15}$ We have also explored including a control for stop-loss (involuntary extension of the term of service), with little effect on the estimated coefficients, in large part due to the fact that fewer than $2 \%$ of individuals experience stop-loss during the sample period. In the end, we chose not to include stop-loss controls, due to the high fraction of missing stop-loss measures in the early years of our sample.
} 
into career fields. Results from this model are similar to the main estimates here, and results are reported in the Appendix.

To estimate the effects of home-state unemployment on reenlistment, $\beta$, we control for year and state fixed effects, state unemployment at entry, as well as the other control variables in the reenlistment analysis, and use state unemployment in the first 3 months after eligibility for discharge as the measure of economic conditions at discharge. This measure of the unemployment rate has the advantage of mirroring the earnings specifications, while possibly sacrificing some precision due to errors in expectations regarding the future value of unemployment at the time of the decision. Most reenlistment occurs in the 12 months leading up to the end of the first contract, and it seems likely that those who reenlist earliest are not marginal reenlisters; however, some of the information in this measure of unemployment may not be available at the time of the decision. The loss in precision should introduce a downward bias in our estimates of $\beta$ and the willingness to pay. We also explore the role of the timing of the decision by excluding those who reenlist before the last year of their initial contract.

Finally, we report the estimated value of unemployment implied by the ratio of reenlistment responses to unemployment and bonus pay, $\beta / \gamma$. Based on the scaling of the bonus, we can interpret this as the percentage of the wage on the next contract (on average, 4 years long) that servicemembers are willing to forgo to avoid a one-point higher unemployment rate at exit. Standard errors using the Delta-method approximation allow us to test for the presence of full insurance, and verify we have the power not just to estimate the responses, but also their ratio.

\subsection{Reenlistment Model Estimates}

Table 2 reports estimates of reenlistment responses and the implied willingness-to-pay for unemployment at exit as a percentage of earnings on the next contract. The upper panel uses individual bonuses at the primary occupation (3-digit) level, while the lower panel averages bonuses and inservice covariates within career fields (2-digit). The primary analysis considers the 1993-2004 time period, while the final two columns on the right extend the sample through 2009.

The reenlistment results are stable across specifications and sample construction. In the first row of Column 1, we find a coefficient of 0.37 on the $\log$ of the bonus, meaning a $10 \%$ increase in pay is associated with just under a $4 \%$ increase in the probability of reenlistment. Off a base of $40 \%$, this implies a reenlistment elasticity just below 1 . Moving across the columns, our estimate is stable in these specifications and time periods. Dropping those who enlist for an initial 3 year term allows us to check for anticipation effects, in either the bonus or unemployment rate, while dropping those who begin service in a small occupation-year cohort provides a check on the potential 
bias introduced in the construction of the bonus variable. Neither has an effect on the estimates. We drop those who reenlist before the last year of the contract in the column titled "Late." With this sample restriction, the response to the bonus increases by about $10 \%$, although the difference is statistically insignificant. These estimates of the bonus response are consistent with the lower range of estimates found in the literature. For example, Asch et al. (2010) finds a value of 1.75 in the 2002-2006 era and Daula and Moffitt (1995) finds a value of 2.2 in 1974-1987, before our sample period, but in the volunteer-era.

We test for the presence of endogeneity using several covariate structures, and by averaging bonuses and in-service covariates within career fields. In the second and third columns, we add controls for reenlistment standards (average AFQT and BMI as measured at initial enlistment of those reenlisting) and then in-service controls for deployment, the receipt of hostile fire pay, promotion speed and base pay. The average AFQT and BMI controls have no effect on the estimates, suggesting that changing reenlistment standards do not substitute for bonus payments. Post-enlistment outcomes such as deployment and hostile fire may be endogenous, and for this reason, we prefer to average them within career fields, as in the lower panel. Regardless, the bonus coefficient, $\gamma$, seems unaffected by these controls, suggesting the endogeneity due to time-varying working conditions is not severe for these cohorts. As this is the primary threat to a (downward) bias in our estimates of $\gamma$, this gives us some confidence in these estimates. Averaging bonuses and in-service controls has modest, statistically insignificant effects on the bonus estimates in the primary specification. Extending the sample through 2009 reveals that the in-service controls are correlated with bonuses and unemployment rates; estimates are stable to their inclusion once this endogeneity is addressed by averaging within career fields.

The response to state unemployment is our clearest qualitative evidence of avoidance behavior, and our estimation allows us to reject the null of no response to unemployment in all specifications. The coefficient of 0.85 in Column 1 means that a 1 point increase in state unemployment increases reenlistment by just under $1 \%$, implying an unemployment elasticity of 2-2.5. Estimates of the reenlistment response to state unemployment rates at the end of the contract are similarly stable across the specifications, with the exception of those using in-service controls in the longer sample period, as discussed above. Estimates range from $0.75-0.8$ in the full sample, and increase to around 1 when the sample is restricted to those who enlist for 4 years or more, and when excluding those who reenlist before the last year of their contract.

Finally, our estimates of the value of avoiding unemployment in terms of bonus points, formed by dividing the reenlistment response to state unemployment by the reenlistment response to bonus pay, imply large welfare losses to unemployment. The coefficient of 2.27 in Column 1 means that 
the marginal reenlister in our sample is roughly indifferent between a 1 percentage point increase in unemployment at exit and a $2.3 \%$ decrease in pay over the course of the next contract. Although we cannot reject the equality of estimates across most specifications, we prefer the lower panel estimates averaged within career fields to address endogeneity and measurement error. Considering the evidence, we take a value of $\beta / \gamma$ equal to $1.5-2$ to be a reasonable, and possibly conservative, value to use in the calibration.

\subsection{Heterogeneity}

Table 3 reports results from the reenlistment model restricted to particular demographic, ability, military pay and branch-of-service groups. We split the sample by white vs non-white (we lack the power to estimate heterogeneity within the non-white group), married vs single, and by service branch, as well as by the mean values of the age at which servicemembers can exit, AFQT and pay. There is modest evidence of heterogeneity in the willingness to pay for labor market conditions at exit, driven almost entirely by variation in the response to the unemployment rate. Effects are largest for servicemembers who are older (above age 23), married, white, and those with higher AFQT and pay. We can reject equality of the responses for the white vs non-white and high vs low pay groups.

The analysis of heterogeneity in willingness-to-pay adds several interpretations to the results. Although the military likely compresses pay differentials relative to the civilian market, responses during recessions are strongest for those with high military pay and AFQT. Presumably these workers have better civilian labor market opportunities, suggesting the response to economic conditions does not hinge on the lack of screening in the reenlistment offers. The evidence is more consistent with the view that military reenlistment offers a safe option for those with stronger labor force attachment, older, married and high-pay workers. Estimates by branch are consistent with this pattern, as the more skilled, career-oriented branches with higher entry standards (Navy and Air Force) show stronger responses to unemployment rates than the branches dominated by infantry (Army and Marines). We also find suggestive evidence of heterogeneity in the discount rates of the subgroups. Responses to pay are largest for married, low AFQT, and low pay servicemembers, for whom the cash-in-hand component of bonuses may induce a larger response.

\section{Effect of Economic Conditions on Earnings of Young Veterans}

Our reduced-form model in this section summarizes the effects of home-state unemployment on the annual earnings of veterans who separate at the end of their first contract, using a similar 
regression specification to other research on labor market transitions. In our main specification we estimate regressions for individual $i$, enlisted for $j(i)$ years on their initial contract, from home state $s$, with initial enlistment contract ending in year $t$, observed $k$ years following the end of their initial contract:

$$
y_{i s t k}=a_{s k}+b_{j(i) t k}+d_{k} U R_{s t}+c \mathbf{X}_{i s t k}+e_{i s t k} .
$$

Our main outcomes of interest are the percentage response of civilian and total earnings to unemployment at the end of the first contract, $U R_{s t}$; plotting the $d_{k}$ coefficients provides the impulse response to a one-percentage-point change in the unemployment rate at the end of the first contract 16 We continue to use the rich set of individual-level control variables described in the reenlistment analysis. Due to data access constraints, the model is estimated in two stages. First, in an individual-level analysis at SSA, we partial out the influence of individual-level background variables on earnings by computing the residual from a regression of earnings on $b_{j(i) t k}$ and $X_{i s t k}$. We then compute average residuals within cells defined by state of enlistment, year of end of contract and year of earnings (dropping cells with 5 or fewer servicemembers; this is less than $1 \%$ of observations). In a second round of analysis, we divide the residual by the average earnings at horizon $k$ (the difference between year of end of initial contract and year of earnings) and regress this normalized residual on the remaining variables. We adopted this strategy to estimate proportional effects without taking the logarithm of zero, although our subsequent analysis revealed no effect on the zero-earnings margin. The model is stacked on $k$, with standard errors clustered at the state level. 17

Identification in this specification arises from the unexpected evolution of $U R_{s t}$ over the course of the initial contract. Lengthy enlistment contracts do most of the work, as serial correlation in state unemployment rates is small at the initial contract horizon. State fixed effects absorb (timeinvariant) regional differences across the US, while the year fixed effect absorbs national business cycles, two important predictors of future unemployment. To address any remaining anticipation of the unemployment rate at the time of exit, we include controls for the state of the economy: state unemployment at enlistment, fixed effects for the interaction of year of entry and year of eligibility, and the interaction of year of eligibility for discharge and year of earnings. Once state and year effects are included, additional controls do not alter the point estimates, giving us confidence that the response of earnings to $U R_{s t}$ represents the causal effect of business cycle conditions at the end

\footnotetext{
${ }^{16}$ For the unemployment rate, we continue to use the unemployment rate in the three months following discharge eligibility; where confusion may arise, we refer to the average unemployment rate in year $t$ as $\overline{U R_{s t}}$.

${ }^{17}$ Data access constraints necessitated this strategy.
} 
of the contract, free of selection effects arising from anticipation.

The characteristics of veterans who exit the military may change with the business cycle, and applying the above specification to the population of young veterans assumes we can capture these changes with our covariates. This selection-on-observables assumption may be plausible, considering our rich set of controls; however, we go one step further and make use of variation in reenlistment rates at the military occupation level to account directly for selection on unobservable characteristics. We define $O(o)$ to be the first digit of the first observed primary occupation code (this is the military MOS code) and use movements in occupation-level reenlistment to construct a control function approach to Heckman's two-step selection correction. In the first stage, we estimate a linear probability model of reenlistment, adding fixed effects for the interaction of $O(o)$ and $t$ to the model. We then include the predicted probability of exit from the first stage in the main earnings equation, using a semi-parametric transformation suggested by Newey (2009):

$$
\begin{aligned}
\mathbb{E}\left[y_{\text {iost } k} \mid D_{\text {iost }}=0\right] & =w_{O(o) k}+a_{s k}+b_{j(i) t k}+d_{k} U R_{s t}+c \mathbf{X}_{\text {istk }}+\Lambda_{k}\left(\widehat{p_{\text {iost }}}\right) \\
\widehat{p_{\text {iost }}} & =z_{O(o) t}+f_{s}+g_{j(i) t}+h U R_{s t}+X_{i s t} .
\end{aligned}
$$

Here, $\widehat{p_{\text {iost }}} \equiv \mathbb{P}\left[D_{\text {iost }}=0\right]$ is the predicted probability of exit, $\Lambda_{k}\left(\widehat{p_{\text {iost }}}\right) \equiv \sum_{l=1}^{4} \lambda_{l}^{k}\left(2 \Phi\left(\widehat{p_{\text {iost }}}\right)-1\right)^{l}$ is the semi-parametric transformation and $\Phi(\bullet)$ is the cumulative distribution function $18 X_{i s t k}$ contains the same variables as the above specifications. The selection-correction is identified by the exclusion of the $z_{O(o) t}$ cross-effect between military occupation and the period of discharge from the earnings equation, where we include only the independent effects of occupation $o$ and year of eligibility $t$ in Equation 5. The occupation-by-year effects have strong predictive power; we reject the null of $z_{1 t}=\ldots=\omega_{O(o) t}=0$ at $p<0.001$. These $O(o) t$ effects reflect the average reenlistment rate in occupation $o$ at time $t$, conditional on changes in the composition of servicemembers with contracts ending in the period. Identification of the selection function with this exclusion restriction requires changes in state-level economic conditions and occupation-level demand to be uncorrelated. In practice, the magnitude of the changes in reenlistment limit the scope for selection.

In a portion of the analysis, we drop those who use a full semester ( 3 or more months) of GI Bill benefits to estimate lower bounds on the earnings effect for the group of young veterans who do not use their GI Bill benefits. Besides continuation in the current job, further education or job training can provide a secondary insurance option. As such, our estimates using those who forgo this option represent lower bounds on the true effect (i.e. corrected for the endogenous choice to

\footnotetext{
${ }^{18}$ In constructing $\widehat{p_{\text {iost }}}$, we set extreme values to 1 and $99 \%$; this is less than $0.0003 \%$ of observations.
} 
forgo their benefits). When we compare estimates from the entire sample to those restricting to non-GI Bill users, we see virtually no difference in the (proportional) effects of unemployment on earnings. We report these results below and provide further details in the Online Appendix.

\subsection{Earnings Results}

Figure 2 graphically displays the earnings losses that result from higher unemployment at discharge for young veterans with initial contracts ending in 1993-2009. We plot three sets of estimates: raw earnings losses, losses corrected for selection out of the military, and civilian earnings losses. Total earnings drop nearly $4 \%$ in the year following separation, and recover slowly. Table 4 reports average earnings, the $d_{k}$ regression coefficients, their standard errors and the implied value of horizon $k$ losses in 2010 dollars, where we use the CPI to deflate nominal income. Negative effects on total earnings remain statistically significant through the 8th year, and point estimates return to zero between the 9th and 10th year. Summing the stream of earnings losses, young veterans lose $\$ 4875$ over the next 10 years for each point increase in home-state unemployment; with a discount factor of 0.9 , the present discounted value of the earnings losses is $\$ 3450$. These results are close to double the (proportional) effect of unemployment among Canadian college graduates estimated in Oreopoulos et al. (2012). We found no statistically-significant effect on the variance of earnings (results not reported).

We evaluate several components of the model in Figure 2 and Table 4, finding that selection into reenlistment, military income (for example, through the reserves) and college benefit use play small roles in the effects. In Figure 2, we plot effects without the selection correction for reenlistment. Selection plays a very small role in the outcome distribution: as expected, correcting for selection increases the size of the effect, but the increase is economically negligible. By considering the effect on civilian sources of earnings (i.e. removing military pay from total earnings), we can address the role of shorter extensions and residual military income earned after discharge. Although there are large effects on civilian income in the year before and year of discharge, they come on a small base of civilian income (see Table 4 for average civilian earnings and year 0 effects). After year 1, effects on civilian income closely track the effects on total income, implying that there is no component of the residual military income that insures veterans against shocks after year 1. We take this as evidence that our definition of reenlistment has left little room for further insurance from maintaining a relationship with the military, for example, through shorter contract extensions, re-joining the military after separation, or service in the Reserves. Similarly, estimates show no meaningful differences when we drop those who use their college benefits in the final columns of Table 4 and in Appendix Figure A2. 
What explains the magnitude of these losses, nearly twice the size of those estimated for college graduates? Period effects appear to be one answer. Davis et al. (2011) finds larger earnings losses for workers displaced during national recessions, and most previous studies of labor market entry used pre-Great Recession samples. In Appendix Figure A3, we disaggregate the analysis by period, revealing that losses are concentrated in years of high national unemployment. Point estimates are near zero in the 1995-2000 and 2004-2006 expansions, while the periods of high national unemployment, from 1992-1994, 2001-2003 and 2007-2009, show large and persistent effects. Even though we include fixed effects for year of eligibility, and hence, absorb the first-order effect of national economic conditions at separation, these estimates reveal that young veterans are (much) more vulnerable to state labor market shocks during times of national recession. The concentration of large earnings losses in the 2007-2009 years may be explained by longer unemployment spells among young veterans during the Great Recession, documented in survey data and several research reports 19

Another concern with interpreting the measured effect of $U R_{s t}$ on losses $k$ years later is that state unemployment rates are themselves persistent. Thus, the measured effect of $U R_{s t}$ on earnings $k$ years after leaving the military confounds any "initial condition" effect of $U R_{s t}$ on outcomes $k$ years later with the direct effect of $\overline{U R_{s t+k}}$. Figure 3 graphically displays the earnings losses that result from higher unemployment for young veterans with initial contracts ending in 19932004. This sample may be more informative regarding the persistence of the earnings effect; as we observe earnings through 2010, this panel is balanced through year 6 . The effects in the earlier 1993-2004 cohort sample appear to be more comparable to other estimates in the literature. Total earnings fall by over $2 \%$ in the year in which the contract ends, and do not return to their expected path until 7 years later. Total losses over 10 years in the 1993-2004 sample are \$4394, with a present discounted value of $\$ 3101$. The results isolating the effect of initial conditions in Table 5 confirm that a significant portion of earnings losses arise from the persistent effect of initial conditions, and cannot be explained by serial correlation in economic conditions. The remaining analysis will focus on the combined effect of initial conditions and serial correlation in economic conditions, as these are the relevant earnings losses for the reenlistment decision.

These earnings losses would be larger if we used a more precise measure of the relevant unemployment rate. There are at least 2 reasons to believe $U R_{s t}$ is mismeasured 20 First, servicemembers have the opportunity to seek early discharge and short extensions that would not meet our definition of reenlistment. We can observe the timing of separation in the administrative data,

\footnotetext{
${ }^{19}$ For example, see Faberman and Foster (2013) and Humensky et al. (2013).

${ }^{20}$ See the Online Appendix for details on these calculations.
} 
and when we use a Wald estimator to correct for the endogenous timing of separation from the military, the estimates increase in magnitude by $17-18 \%$. Second, veterans are a highly mobile population. We lack data on the post-service migration of young veterans, however, we can use the Current Population Survey, ACS and NLSY to examine aggregate patterns in veterans migration. When we correct for the resulting mismeasurement of the unemployment rate, the earnings effects above are magnified by as much as $20 \%$. Together, these corrections will increase the estimated effects above from $3.6 \%$ of earnings lost to a percentage point increase in unemployment up to close to $5 \%$ (and from $2.2 \%$ to above $3 \%$ in the 1993-2004 period). These are large losses for this literature, independent of period effects.

Once removing period effects, there are several explanations for the larger earnings losses among young veterans. First, recent research finds evidence of socioeconomic and age gradients in cyclical employment losses, meaning that it is possible young veterans differ from the workers in these previous studies in ways that make them more vulnerable to business cycle shocks. Faberman and Foster (2013) assesses this hypothesis (related to unemployment during the Great Recession) using data from the Current Population Survey, finding little empirical support for demographics or occupations to explain differences in veteran and non-veteran outcomes. Second, young veterans may have experience larger losses due to the nature of military service. For example, young veterans may have difficulty expanding their job search while on active-duty or deployed. We have tried interacting deployment indicators and state unemployment rates in the willingness-to-pay model, but did not find a significant effect, albeit in a largely pre-Great Recession sample.

Finally, it is possible young veterans may have better access to mitigating mechanisms, meaning that they are more able to absorb economic shocks through reduced earnings, without sacrificing consumption or other sources of utility. One of the most important differences between young veterans and similar workers is the specific public programs available to veterans. Young veterans have access to one of the most generous education/job-training benefits in the US economy through the G.I. Bill, which includes stipends for living expenses. During this era, veterans have been the target of: federal tax-credits to encourage their hiring, especially if they have a service-connected disability (Heaton, 2012); preferential hiring by local, state and the federal government; matching grants to schools (the Yellow Ribbon program); as well as numerous community efforts to encourage their hiring. Veterans who fall on hard times can access the means-tested health care services available through the Veterans Administration, as well as a host of services targeted at homeless veterans. Disabled veterans have access to Vocational Rehabilitation and Employment, a program designed to find them work. These options available specifically to veterans amount to additional mitigating mechanisms, and economic theory suggests that additional margins of response would 
lead agents to bear smaller welfare costs for an observed level of lost earnings, and hence, be more willing to bear earnings losses. For this reason, earnings losses may overstate the effect for similar workers, while willingness-to-pay will understate the costs to workers who do not have access to the same mitigating mechanisms.

\section{Willingness To Pay and Mitigating Mechanisms}

In this section, we use our reenlistment model estimates to calibrate the willingness to pay for exit over the business cycle. We then use these estimates, along with our earnings estimates from Section 3, to quantify the value of mitigating mechanisms.

We define mitigating mechanisms, $M$, as the difference between the earnings losses and WTP:

$$
M=\Delta y\left(U R_{s t}\right)-W T P=\Delta y\left(U R_{s t}\right)-\frac{\beta}{\gamma} \Delta y^{b o n u s}\left(B_{i o t}\right)
$$

where $\Delta y\left(U R_{s t}\right)=\sum_{k \geq 0} \rho^{k} d_{k} y_{k}$, the discounted sum of earnings losses estimated in the previous section, and $\Delta y^{\text {bonus }}\left(B_{\text {iot }}\right)$ is the discounted value of a $1 \%$ increase in bonus payments. Although we refer to $M$ as mitigating, nothing constrains $M>0$. For example, it is possible that young veterans may be willing to give up more than their earnings losses to avoid entering the civilian labor market if unemployment, or adjustments to it, entail a psychic cost in addition to lost earnings. The share of earnings losses left unexplained by WTP we attribute to mitigating mechanisms, $m$, so $m \equiv \frac{M}{\Delta y(U R)}=1-\frac{W T P}{\Delta y(U R)}$. This comparison weighs a risky stream of income against a sure bonus payment, a comparison which introduces a biases towards finding a smaller offset. We chose this specification in part because the estimation could not detect an effect of the unemployment rate on the variance of earnings.

In order to calibrate the total value of bonus payments, we need to specify how $\Delta y^{\text {bonus }}\left(B_{i o t}\right)$ turns our measure of bonus incentives into dollar-valued payments. This function uses the rules regarding the size and timing of bonus payments, in addition to estimates of the persistence of bonuses across contract, to translate the a $1 \%$ increase in bonus multiplier, $\gamma$, into a discounted dollar value. In terms of size, the bonus pays the multiple of the length of reenlistment, the bonus multiplier and the base pay of servicemembers. To account for timing, we decompose the value of a bonus payments into three payment streams. First, half of the bonus is paid as a lump-sum on signing. Second, the remaining half of the bonus is spread over the course of the next contract. Third, the bonus offered at the end of the first contract is predictive of the bonus offered at the end of the second contact. To address this persistence of offered bonuses, we calibrate our estimates 
using the averages of second-term contract length and reenlistment. Second-term contracts average a 4 year commitment (average second contract length is 49 months between 1993 and 2004). At the next decision point, $25 \%$ of the bonus $55 \%$ of servicemembers will reenlistment. Pulling together these components, we specify the dollar value of the bonus as,

$$
\begin{aligned}
\Delta y^{\text {bonus }}\left(B_{\text {iot }}\right) & =y_{t}^{\text {mil }}\left(2 \%+\frac{1}{2} 0.5 \%+\rho 0.5 \%+\rho^{2} 0.5 \%+\rho^{3} 0.5 \%+\frac{1}{2} \rho^{4} 0.5 \%\right) \\
& +\rho^{4}(0.55)(0.25) y_{t+4}^{m i l}\left(2 \%+\frac{1}{2} 0.5 \%+\rho 0.5 \%+\rho^{2} 0.5 \%+\rho^{3} 0.5 \%+\frac{1}{2} \rho^{4} 0.5 \%\right) .
\end{aligned}
$$

The 4 units of bonus, reflecting the 4 additional years of new service commitment, are paid as 2 units in year 0 , and half a unit per year served after that. Since the reenlistment occurs, on average, midway through the year, the servicemember receives 2.25 of the 4 bonus units in the year of reenlistment, half a unit for the next 3 years, and a quarter of a unit in the last year of the contract. We set $y_{t}^{m i l}=\$ 32,000$, average reenlistment-year base military earnings in 2010 dollars, meaning that each bonus point equates to a stream of payments (over the course of a 4 year contract) of $\$ 640$ and $\$ 80$ in year $0, \$ 160$ in years 1 through 3 and $\$ 80$ in year 4 . After the second contract is concluded, we assume that continuation occurs at the average rate, and those who continue are paid at the average persistence of bonuses. This implies that $55 \%$ will continue, with $25 \%$ of the unexpected component of the 1 st contract bonus persisting. Following the second contract, we assume the servicemember exits. This is consistent with the reduced-form evidence showing that the increase in military income (in response to home-state unemployment) is statistically significant for 9 years following the end of the first contract.

We choose the discount rate to reflect previous estimates in the literature. Daula and Moffitt (1995) estimates a discount rate between $10 \%$ and 14\% for enlisted men in 1974-1990 (before our sample period, but during the post-1973 volunteer era), while Warner and Pleeter (2001) estimates rates above $18 \%$ for $90 \%$ of enlisted men in 1996. These values are large, and some researchers have suggested that observed rates may be influenced by credit constraints or behavioral elements, such as impatience. We consider annual discount factors of $95 \%, 90 \%$ and $80 \%$. At this level of discounting, option-value behavior at reenlistment decisions made at the end of future contracts plays a small role in the model.

The key input in our calibration is the ratio of regression parameters, $\beta / \gamma$, which was estimated

${ }^{21}$ Appendix Figure A4 displays the histogram of second contract lengths. To estimate the persistence of the bonus, we use the framework of the reenlistment model section to predict the bonus offered at the conclusion of the second contact with the the bonus offered at the end of the first contract. 
in Section 2. Consistent with the range of estimates we found above, we calibrate WTP for values of $\beta / \gamma$ ranging from 1 up to 2.5. These values cover the upper and lower range of our estimates and in the previous literature on the reenlistment elasticity. The wide range of $\gamma$ estimates are the primary source of uncertainty in our calibration.

\subsection{Results: Mitigating Mechanisms}

Table 6 displays the results of our calibration. We vary the discount rate across the columns and $\beta / \gamma$ across the rows. The first row of estimates, labeled $\Delta y(U R)$, reflects the discounted sum of earnings losses estimated in Section 3 . In parentheses we translate this into the fraction of discounted lifetime income lost to a 1 point increase in the unemployment rate. Naturally, as we increase the discount rate the value of the earnings losses falls, but the importance of one year's income in permanent income rises. We use a conservative discount factor of $\rho=0.9$ in our preferred specification. At this level, the PDV of earnings losses is $\$ 3101$, equating to a $1.31 \%$ drop in the PDV of lifetime income. In the remaining portion of the table, we compare these earnings losses to the implied WTP, calibrated according to the assumptions above.

Our calibration returns a range of values for the mitigating mechanisms, primarily reflecting uncertainty in estimates of $\gamma$ in Section 2. Our median estimate is $\beta / \gamma \approx 2$, where WTP $=\$ 2706$ (if $\rho=0.9$ ), and mitigating mechanisms account for $13 \%$ of earnings losses. At these parameter values, servicemembers are willing to give up $1.14 \%$ (87\% of $1.31 \%$ ) of permanent income in exchange for a 1 point decrease in unemployment at the time of exit. Instead, if we let $\beta / \gamma=1.5$, corresponding to the lower range of estimates in Table 2 and to a reenlistment elasticity of 1.75 (which is similar to values estimated in the military manpower literature), we find that WTP = $\$ 2029$, and mitigating mechanisms account for $35 \%$ of earnings losses. For a given value of the reenlistment elasticity, the choice of the discount rate has a moderate influence on the calibration of mitigating mechanisms. For example, at $\beta / \gamma=1.5$, the low and high values of the discount factor result in mitigating mechanisms offsetting between $20 \%$ and $41 \%$ of earnings losses. The results of the calibration reveal that mitigating mechanisms shield only a small share of earnings losses, and we are quite far from the extreme case of full insurance.

Finally, these calibration results likely understate the true dollar value of losses for two reasons. First, using Wald estimators to adjust the estimates for mismeasured unemployment rates at exit (as discussed in Section 3) would result in correspondingly larger earnings losses and WTP (since the same mismeasured unemployment rate enters both calculations); however, the resulting share of earnings offset by mitigating mechanisms will not be affected, since it is the ratio of these two. Second, while most reenlistment decisions occur in the final 6 months of the initial enlist- 
ment contract, in some years and for some occupations, reenlistment windows may open 2 years or more before the end of the contract. In these situations, high discount rates can have serious consequences, inducing reenlistment in response to bonus offers due to the cash-in-hand component, rather than through the comparison of the exit and reenlistment options from the point of view of the agent the end of the contract, as we have modeled servicemembers in this paper. In particular, at a horizon of 2 years, the projection of the state unemployment rate will be far less precise than for decisions made at the end of the contract, limiting the potential response of early reenlistment to this variable. In combination, the cash-in-hand component of bonus pay and error in unemployment projections imply a smaller unemployment rate response $(\beta)$ and larger response to bonus pay $(\gamma)$ for decisions made significantly before the end of the contract.

\section{Conclusion}

In this paper, we examine the consequences for the earnings and welfare of young US veterans who enter the labor market in times of high unemployment. We measure the dollar value of utility lost in the transition to civilian employment when unemployment is 1 point higher in the young veteran's home state to be between \$2029 and \$2706 (in discounted 2010 dollars). These values imply that between 13 and $35 \%$ of the estimated $\$ 3101$ in earnings losses are offset by mitigating mechanisms. Welfare effects among this group of workers likely understate the degree to which earnings losses are offset for other, similar workers, as young veterans have better access to (publicly-provided) mitigating mechanisms than almost any other similar group of young workers in the US economy. For instance, in addition to the usual informal insurance provided by private transfers, young veterans are eligible for very generous college/job-training tuition benefits, a dedicated unemployment insurance system (Unemployment Compensation for Ex-Servicemembers), hiring tax benefits, and health insurance.

The welfare cost of business cycles is an fundamental question in economics, and a number of summary measures of welfare costs precede this study. We add to this literature in three ways. First, we provide a new and direct measure of welfare costs of local labor market shocks based on the observation of the decision to enter a labor market with a well-defined outside option. Our estimate of willingness-to-pay summarizes the welfare losses to job search over the business cycle, without assumptions regarding consumption and savings behavior or a model of the labor market and its parameters. As the measure is one of avoidance behavior, it captures direct costs to the worker in the form of lost labor market opportunities, as well as difficult-to-measure indirect costs. We estimate the hedonic value of unemployment, which includes the contributions to utility from health, happiness and general equilibrium effects, all of which have been shown to 
respond to business-cycle conditions ${ }^{22}$ A recent literature estimates the fiscal costs of job creation ${ }^{23}$ however, fewer papers estimate the net benefits of job creation; our measure takes a step in this direction. Second, we link the welfare costs of these local labor market shocks to the earnings losses of workers exposed to the shock. This allows us to compare the welfare costs to the actual earnings losses of workers, and estimate the share offset by mitigating mechanisms. Although we made several conservative assumptions, the share of earnings offset by mitigating mechanisms remained no larger than a third. In an Appendix, we recover an estimate of the labor supply elasticity implied by the low offset, finding it to be quite close to zero. We believe these estimates would be lower bounds for other similar workers, given the range of public programs available to these workers. Finally, we extend the literature on the earnings effects of labor market search over the business cycle to a new group of workers, young US veterans. Most citizens and policymakers recognize that this groups is owed a particular debt based on their service to the country. As a consequence, veterans are the target of a large number of public programs; however, data limitations present a challenge in studying their transition from military to civilian life. In the future, we hope military reenlistment can serve as a unique laboratory for the study of local labor market shocks. Large-scale studies of the effects of economic conditions at the time of job search have been limited by data coverage, with a focus on older, tenured and college-educated workers, due to both data availability and the lack of a clear natural experiment, such as the one analyzed here.

\section{References}

Altonji, J. G., L. B. Kahn, and J. Speers (2016). Cashier or Consultant? Entry Labor Market Conditions, Field of Study, and Career Success. Journal of Labor Economics 34(S1).

Asch, B. J., P. Heaton, J. Hosek, F. Martorell, C. Simon, and J. T. Warner (2010). Cash Incentives and Military Enlistment, Attrition, and Reenlistment. Technical report, DTIC Document.

Ashenfelter, O. (1980). Unemployment as Disequilibrium in a Model of Aggregate Labor Supply. Econometrica 48(3), pp. 547-564.

\footnotetext{
${ }^{22} \mathrm{~A}$ similar exercise to ours is performed by Blanchflower and Oswald (2004), using self-reported happiness as the outcome (in place of reenlistment), and reports of being unemployed as the explanatory variable of interest, finding unemployment to be worth approximately $\$ 60,000$, a very large value. As in our estimation, the uncertainty in this estimate appears to arise from the price elasticity of happiness (or in our case, reenlistment), rather than the correlation between unemployment and (un)happiness, which appears quite strong. See Ruhm (2000) and Stevens et al. (2015) for evidence on countercyclical patterns in health and mortality.

${ }^{23}$ See, for example, Nakamura and Steinsson (2011), Serrato and Wingender (2014) and Chodorow-Reich et al. (2012).
} 
Blanchflower, D. G. and A. J. Oswald (2004). Well-being Over Time in Britain and the USA. Journal of Public Economics 88(78), 1359 - 1386.

Blundell, R., L. Pistaferri, and I. Preston (2008, September). Consumption Inequality and Partial Insurance. American Economic Review 98(5), 1887-1921.

Blundell, R., L. Pistaferri, and I. Saporta-Eksten (2015). Consumption Inequality and Family Labor Supply. American Economic Review. Forthcoming.

Chetty, R. (2009, 05). Sufficient Statistics for Welfare Analysis: A Bridge Between Structural and Reduced-Form Methods. Annual Review of Economics 1(1), 451-488.

Chetty, R. and A. Szeidl (2007). Consumption Commitments and Risk Preferences. The Quarterly Journal of Economics 122(2), 831-877.

Chodorow-Reich, G., L. Feiveson, Z. Liscow, and W. G. Woolston (2012). Does State Fiscal Relief during Recessions Increase Employment? Evidence from the American Recovery and Reinvestment Act. American Economic Journal: Economic Policy 4(3), 118-45.

Clark, A. E. and A. J. Oswald (1994). Unhappiness and Unemployment. The Economic Journal 104(424), 648-659.

Cochrane, J. H. (1991, October). A Simple Test of Consumption Insurance. Journal of Political Economy 99(5), 957-76.

Daula, T. and R. Moffitt (1995). Estimating Dynamic Models of Quit Behavior: The Case of Military Reenlistment. Journal of Labor Economics 13(3), pp. 499-523.

Davis, S. J., T. V. Wachter, R. E. Hall, and R. Rogerson (2011). Recessions and the Costs of Job Loss [with Comments and Discussion]. Brookings Papers on Economic Activity Fall, pp. 1-72.

Deaton, A. (2012). The Financial Crisis and the Well-being of Americans: 2011 OEP Hicks Lecture. Oxford Economic Papers 64(1), 1-26.

Di Tella, R., J. Haisken-De New, and R. MacCulloch (2010, December). Happiness Adaptation to Income and to Status in an Individual Panel. Journal of Economic Behavior \& Organization 76(3), 834-852.

Di Tella, R., R. J. MacCulloch, and A. J. Oswald (2003). The Macroeconomics of Happiness. The Review of Economics and Statistics 85(4), 809-827. 
Faberman, J. and T. Foster (2013). Unemployment Among Recent Veterans During the Great Recession. Economic Perspectives 37(Q I), 1-13.

Genda, Y., A. Kondo, and S. Ohta (2010). Long-Term Effects of a Recession at Labor Market Entry in Japan and the United States. Journal of Human Resources 45(1), 157-196.

Greenstone, M., S. P. Ryan, and M. Yankovich (2014). The Value of a Statistical Life: Evidence from Military Retention Incentives and Occupation-Specific Mortality Hazards. Unpublished Working Paper.

Gruber, J. (1997). The Consumption Smoothing Benefits of Unemployment Insurance. The American Economic Review 87(1), pp. 192-205.

Heaton, P. (2012). The Effects of Hiring Tax Credits on Employment of Disabled Veterans. Technical report, RAND Occasional Papers.

Helliwell, J. F. and H. Huang (2014). New Measures of the Costs of Unemployment: Evidence from the Subjective Well-Being of 3.3 Million Americans. Economic Inquiry 52(4), 1485-1502.

Hosek, J. and F. Martorell (2009). How Have Deployments During the War on Terrorism Affected Reenlistment? (1 ed.). RAND Corporation.

Hoynes, H., D. L. Miller, and J. Schaller (2012). Who Suffers During Recessions? The Journal of Economic Perspectives 26(3), 27-47.

Humensky, J. L., N. Jordan, K. T. Stroupe, and D. M. Hynes (2013). How Are Iraq/AfghanistanEra Veterans Faring in the Labor Market? Armed Forces \& Society 39(1), 158-183.

Jacobson, L. S., R. J. LaLonde, and D. G. Sullivan (1993). Earnings Losses of Displaced Workers. The American Economic Review 83(4), 685-709.

Kahn, L. B. (2010). The Long-term Labor Market Consequences of Graduating from College in a Bad Economy. Labour Economics 17(2), 303-316.

Krebs, T. (2007). Job Displacement Risk and the Cost of Business Cycles. American Economic Review 97(3), 664-686.

Krusell, P., T. Mukoyama, A. Sahin, and J. Anthony A. Smith (2009, July). Revisiting the Welfare Effects of Eliminating Business Cycles. Review of Economic Dynamics 12(3), 393-402. 
Nakamura, E. and J. Steinsson (2011). Fiscal Stimulus in a Monetary Union: Evidence from U.S. Regions. NBER Working Papers 17391, National Bureau of Economic Research, Inc.

Newey, W. K. (2009). Two-step Series Estimation of Sample Selection Models. The Econometrics Journal 12, S217-S229.

Oreopoulos, P., T. von Wachter, and A. Heisz (2012, January). The Short- and Long-Term Career Effects of Graduating in a Recession. American Economic Journal: Applied Economics 4(1), $1-29$.

Ruhm, C. J. (2000). Are Recessions Good for Your Health? The Quarterly Journal of Economics 115(2), 617-650.

Saez, E., J. Slemrod, and S. H. Giertz (2012). The Elasticity of Taxable Income with Respect to Marginal Tax Rates: A Critical Review. Journal of Economic Literature 50(1), 3-50.

Schaller, J. and A. H. Stevens (2015). Short-run Effects of Job Loss on Health Conditions, Health Insurance, and Health Care Utilization. Journal of Health Economics 43(C), 190-203.

Schulhofer-Wohl, S. (2011). Heterogeneity and Tests of Risk Sharing. Journal of Political Economy 119(5), pp. 925-958.

Serrato, J. C. and P. Wingender (2014). Estimating Local Fiscal Multipliers. Working Paper.

Simon, C. J., S. Negrusa, and J. T. Warner (2010). Educational Benefits and Military Service: An Analysis of Enlistment, Reenlistment, and Veterans' Benefit Usage 1991-2005. Economic Inquiry 48(4), 1008-1031.

Stevens, A. H., D. L. Miller, M. E. Page, and M. Filipski (2015, November). The Best of Times, the Worst of Times: Understanding Pro-cyclical Mortality. American Economic Journal: Economic Policy 7(4), 279-311.

Sullivan, D. and T. von Wachter (2009). Job Displacement and Mortality: An Analysis Using Administrative Data. The Quarterly Journal of Economics 124(3), 1265-1306.

Warner, J. T. and S. Pleeter (2001, September). The Personal Discount Rate: Evidence from Military Downsizing Programs. American Economic Review 91(1), 33-53.

Wolfers, J. (2003). Is Business Cycle Volatility Costly? Evidence from Surveys of Subjective Well-Being. International Finance 6(1), 1-26. 
Table 1: Summary Statistics

\begin{tabular}{|c|c|c|c|c|c|c|c|c|}
\hline & \multicolumn{4}{|c|}{ All Enlisted Men: 1993-2004 } & \multicolumn{4}{|c|}{ "Young Veterans: 1993-2004 } \\
\hline & Mean & SD & p10 & p90 & Mean & SD & p10 & p90 \\
\hline Age at Entry & 20.09 & 2.37 & 18 & 23 & 20.00 & 2.23 & 18 & 23 \\
\hline Age at End of Term & 23.93 & 2.40 & 22 & 27 & 23.80 & 2.27 & 22 & 26 \\
\hline AFQT at Entry & 58.20 & 17.52 & 35 & 82 & 58.11 & 17.55 & 35 & 82 \\
\hline Ed. $>$ HS at Entry & 0.10 & & & & 0.09 & & & \\
\hline Ed. $>$ HS at End of Term & 0.15 & & & & 0.14 & & & \\
\hline Single at Entry & 0.88 & & & & 0.90 & & & \\
\hline Single at End of Term & 0.61 & & & & 0.66 & & & \\
\hline White & 0.64 & & & & 0.68 & & & \\
\hline Black & 0.19 & & & & 0.17 & & & \\
\hline Hispanic & 0.10 & & & & 0.10 & & & \\
\hline Initial Term (years) & 3.89 & 0.57 & 3 & 4 & 3.86 & 0.56 & 3 & 4 \\
\hline Second Term (months) & 49.78 & 12.78 & 35 & 71 & 49.56 & 13.31 & 35 & 71 \\
\hline Base Pay (monthly) & 1941 & 167 & 1729 & 2171 & 1914 & 152 & 1729 & 2171 \\
\hline Bonus Offer (if $>0$ ) & 11340 & 7287 & 4480 & 23000 & 10757 & 6678 & 4469 & 21239 \\
\hline Offered Bonus & 0.52 & & & & 0.50 & & & \\
\hline Army & 0.38 & & & & 0.38 & & & \\
\hline Navy & 0.27 & & & & 0.25 & & & \\
\hline Marines & 0.17 & & & & 0.22 & & & \\
\hline Air Force & 0.19 & & & & 0.15 & & & \\
\hline $\mathrm{N}$ & 690,148 & & & & 411,920 & & & \\
\hline
\end{tabular}

Notes: Descriptive statistics for All Enlisted Men with initial enlistment contracts ending between 1993 and 2004, and the subgroup of Young Veterans, defined as enlisted men who do not reenlist by the end of the first contract. 2010 dollars.

Yagan, D. (2013). Moving to Opportunity? Migratory Insurance over the Great Recession. Unpublished Working Paper. 
Table 2: Effect of Bonus and Unemployment Rate on Reenlistment

\begin{tabular}{|c|c|c|c|c|c|c|c|c|c|}
\hline & \multicolumn{7}{|c|}{ 1993-2004 } & \multicolumn{2}{|c|}{ 1993-2009 } \\
\hline & All & All & All & $j \geq 4 \mathrm{y}$ & $j \geq 4 \mathrm{y}$ & $N_{o t} \geq 15$ & Late & All & All \\
\hline \multicolumn{10}{|c|}{ A. Individual-level Bonus and Controls } \\
\hline Bonus $(\gamma)$ & $\begin{array}{c}0.37 * * * \\
(0.04)\end{array}$ & $\begin{array}{c}0.37 * * * \\
(0.04)\end{array}$ & $\begin{array}{c}0.31 * * * \\
(0.04)\end{array}$ & $\begin{array}{c}0.36 * * * \\
(0.04)\end{array}$ & $\begin{array}{c}0.31 * * * \\
(0.05)\end{array}$ & $\begin{array}{c}0.38 * * * \\
(0.04)\end{array}$ & $\begin{array}{c}0.32 * * * \\
(0.05)\end{array}$ & $\begin{array}{c}0.37 * * * \\
(0.04)\end{array}$ & $\begin{array}{c}0.31 * * * \\
(0.04)\end{array}$ \\
\hline $\mathrm{UR}(\beta)$ & $\begin{array}{c}0.85 * * * \\
(0.19)\end{array}$ & $\begin{array}{c}0.85 * * * \\
(0.19)\end{array}$ & $\begin{array}{c}0.86 * * * \\
(0.22)\end{array}$ & $\begin{array}{c}1.06 * * * \\
(0.19)\end{array}$ & $\begin{array}{c}1.09 * * * \\
(0.24)\end{array}$ & $\begin{array}{c}0.86^{* * *} \\
(0.19)\end{array}$ & $\begin{array}{c}0.94 * * * \\
(0.21)\end{array}$ & $\begin{array}{c}0.83 * * * \\
(0.15)\end{array}$ & $\begin{array}{c}1.49 * * * \\
(0.18)\end{array}$ \\
\hline$\beta / \gamma$ & $\begin{array}{c}2.27 * * * \\
(0.63)\end{array}$ & $\begin{array}{c}2.27 * * * \\
(0.63)\end{array}$ & $\begin{array}{c}2.81 * * * \\
(0.84)\end{array}$ & $\begin{array}{c}2.90 * * * \\
(0.70)\end{array}$ & $\begin{array}{c}3.48 * * * \\
(0.97)\end{array}$ & $\begin{array}{c}2.24 * * * \\
(0.61)\end{array}$ & $\begin{array}{c}2.88 * * * \\
(0.90)\end{array}$ & $\begin{array}{c}2.28 * * * \\
(0.55)\end{array}$ & $\begin{array}{c}4.74 * * * \\
(0.83)\end{array}$ \\
\hline \multicolumn{10}{|c|}{ B. Career-Field Mean Bonus and Controls } \\
\hline$\overline{\text { Bonus }(\gamma)}$ & $\begin{array}{c}0.40 * * * \\
(0.06)\end{array}$ & $\begin{array}{c}0.40 * * * \\
(0.06)\end{array}$ & $\begin{array}{c}0.41 * * * \\
(0.06)\end{array}$ & $\begin{array}{c}0.40 * * * \\
(0.06)\end{array}$ & $\begin{array}{c}0.41 * * * \\
(0.06)\end{array}$ & $\begin{array}{c}0.42 * * * \\
(0.06)\end{array}$ & $\begin{array}{c}0.32 * * * \\
(0.07)\end{array}$ & $\begin{array}{c}0.50 * * * \\
(0.07)\end{array}$ & $\begin{array}{r}0.51^{* * * *} \\
(0.04)\end{array}$ \\
\hline $\mathrm{UR}(\beta)$ & $\begin{array}{c}0.77 * * * \\
(0.18)\end{array}$ & $\begin{array}{c}0.77 * * * \\
(0.18)\end{array}$ & $\begin{array}{c}0.76 * * * \\
(0.18)\end{array}$ & $\begin{array}{c}0.96 * * * \\
(0.19)\end{array}$ & $\begin{array}{c}0.95 * * * \\
(0.19)\end{array}$ & $\begin{array}{c}0.78 * * * \\
(0.18)\end{array}$ & $\begin{array}{c}0.88 * * * \\
(0.20)\end{array}$ & $\begin{array}{c}0.82 * * * \\
(0.14)\end{array}$ & $\begin{array}{c}0.83 * * * \\
(0.14)\end{array}$ \\
\hline$\beta / \gamma$ & $\begin{array}{c}1.95^{* * * *} \\
(0.56)\end{array}$ & $\begin{array}{c}1.93 * * * \\
(0.55)\end{array}$ & $\begin{array}{c}1.84 * * * \\
(0.52)\end{array}$ & $\begin{array}{c}2.42 * * * \\
(0.61)\end{array}$ & $\begin{array}{c}2.31 * * * \\
(0.62)\end{array}$ & $\begin{array}{c}1.86^{* * *} \\
(0.50)\end{array}$ & $\begin{array}{c}2.70 * * * \\
(0.84)\end{array}$ & $\begin{array}{c}1.64 * * * \\
(0.39)\end{array}$ & $\begin{array}{r}1.63^{* * * *} \\
(0.34)\end{array}$ \\
\hline $\begin{array}{l}\text { Mean AFQT, BMI } \\
\text { In-service } X_{i}\end{array}$ & & $\mathrm{x}$ & $\begin{array}{l}\mathrm{x} \\
\mathrm{x}\end{array}$ & $\mathrm{X}$ & $\begin{array}{l}\mathrm{x} \\
\mathrm{x}\end{array}$ & $\mathrm{x}$ & $\mathrm{X}$ & $\mathrm{X}$ & $\begin{array}{l}\mathrm{x} \\
\mathrm{x}\end{array}$ \\
\hline $\begin{array}{l}\text { Career Fields } \\
\mathrm{N}\end{array}$ & $\begin{array}{c}392 \\
690,148\end{array}$ & $\begin{array}{c}374 \\
689,058\end{array}$ & $\begin{array}{c}359 \\
686,295\end{array}$ & $\begin{array}{c}370 \\
550,094\end{array}$ & $\begin{array}{c}356 \\
548,353\end{array}$ & $\begin{array}{c}218 \\
676,562\end{array}$ & $\begin{array}{c}357 \\
616,334\end{array}$ & $\begin{array}{c}402 \\
984,916\end{array}$ & $\begin{array}{c}387 \\
981,470\end{array}$ \\
\hline
\end{tabular}

Notes: Table reports results of regressions of reenlistment on bonus incentives and state unemployment rates with a rich set of controls (see text for details). The ratio of regression coefficients, $\beta / \gamma$, represents the willingness-to-pay (as a percentage of earnings on the next contract) for reenlistment in response to changes in home state economic conditions. Sample composed of all enlisted servicemembers at end of first contract with other sample restrictions noted in column headers: all contracts, initial contracts of at least 4 years $(j \geq 4 \mathrm{y})$, dropping small occupations $\left(N_{o t} \geq 15\right)$ and restricting to reenlistments occurring in the last year of the contract (Late). s.e. clustered by career field and state of enlistment. Significance levels: $* * * \mathrm{p}<1 \%, * * \mathrm{p}<5 \%, * \mathrm{p}<10 \%$. 
Table 3: Heterogeneity in Reenlistment Responses, 1993-2004

\begin{tabular}{lccc}
\hline & UR & Bonus & WTP \\
\hline Eligible $>$ Age 23 & $0.88^{* * *}$ & $0.38^{* * *}$ & $2.32^{* * *}$ \\
& $(0.20)$ & $(0.07)$ & $(0.70)$ \\
Eligible $\leq$ Age 23 & $0.60^{* *}$ & $0.40^{* * *}$ & $1.50^{* *}$ \\
& $(0.24)$ & $(0.06)$ & $(0.63)$ \\
\hline White & $1.01^{* * *}$ & $0.37^{* * *}$ & $2.72^{* * *}$ \\
& $(0.17)$ & $(0.07)$ & $(0.70)$ \\
Non-White & 0.04 & $0.42^{* * *}$ & 0.08 \\
& $(0.24)$ & $(0.06)$ & $(0.58)$ \\
\hline Single & $0.59^{* * *}$ & $0.35^{* * *}$ & $1.71^{* * *}$ \\
& $(0.17)$ & $(0.07)$ & $(0.63)$ \\
Married & $1.24^{* * *}$ & $0.48^{* * *}$ & $2.59^{* * *}$ \\
& $(0.26)$ & $(0.07)$ & $(0.70)$ \\
\hline AFQT $>59$ & $0.94^{* * *}$ & $0.38^{* * *}$ & $2.48^{* * *}$ \\
& $(0.20)$ & $(0.05)$ & $(0.64)$ \\
AFQT $\leq 59$ & $0.67 * * *$ & $0.47^{* * *}$ & $1.43^{* * *}$ \\
& $(0.23)$ & $(0.08)$ & $(0.54)$ \\
\hline High Pay & $0.96^{* * *}$ & $0.36^{* * *}$ & $2.64 * * *$ \\
& $(0.21)$ & $(0.08)$ & $(0.70)$ \\
Low Pay & 0.26 & $0.47^{* * *}$ & 0.55 \\
& $(0.18)$ & $(0.12)$ & $(0.39)$ \\
\hline Army & 0.17 & $0.32^{* * *}$ & 0.52 \\
& $(0.29)$ & $(0.12)$ & $(0.96)$ \\
Navy & $1.10^{* * *}$ & $0.55^{* * *}$ & $2.01^{* * *}$ \\
& $(0.27)$ & $(0.11)$ & $(0.66)$ \\
Marines & $0.49^{* *}$ & $0.37^{* * *}$ & $1.30^{* *}$ \\
& $(0.25)$ & $(0.07)$ & $(0.63)$ \\
Air Force & $1.78^{* * *}$ & $0.40^{* * *}$ & $4.46^{* *}$ \\
& $(0.47)$ & $(0.12)$ & $(2.04)$ \\
\hline \hline & & &
\end{tabular}

Notes: Table reports coefficients from reenlistment model with WTP, the ratio of regression coefficients on unemployment and bonus. Sample restrictions noted in first column. Pay, age and AFQT samples divided at the mean value of varaible. Significance levels: $* * * \mathrm{p}<1 \%,{ }^{* *} \mathrm{p}<5 \%, * \mathrm{p}<10 \%$. 
Table 4: Earnings: 1993-2009 Cohorts, Civilian Earnings and Selection

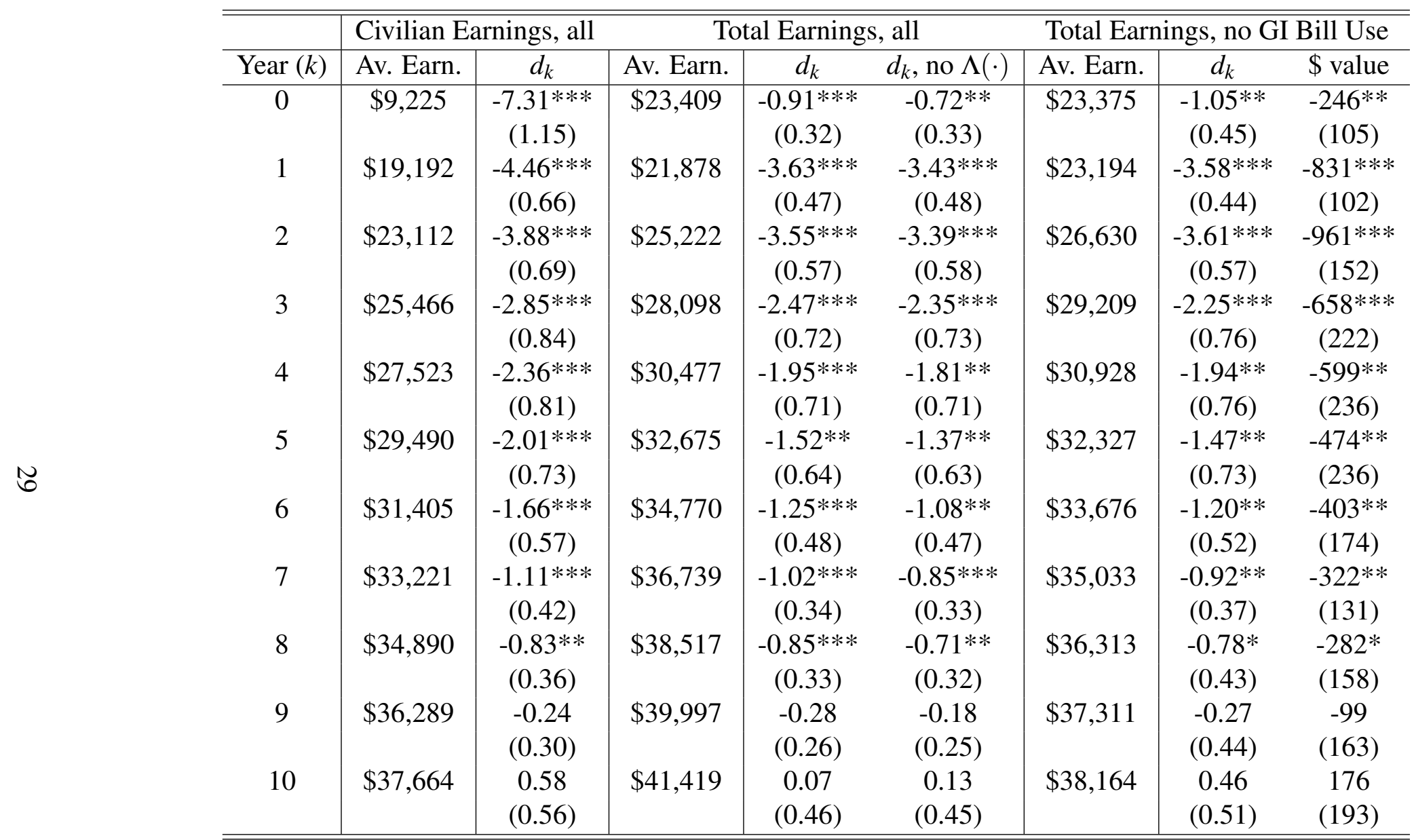

Notes: Table reports average total earnings and regression coefficients on state unemployment in the 3 months following eligibility $\left(d_{k}\right.$, from Equation 5. Sample composed of an unbalanced panel of all enlisted men who separate at the end of their first contract. In Columns 2 and 3 we report results on the civilian component of earnings, in Columns 4-5 we report the full sample result (with the selection correction), in Column 6 we report the effects without the selection correction (i.e. excluding $\Lambda(\cdot)$ from the estimation) and in columns 7-9 we report estimates for those who do not use their GI Bill. Real $2010 \$(\mathrm{CPI})$. s.e. clustered by state of enlistment. Significance levels: $* * * \mathrm{p}<1 \%$, $* *$ $\mathrm{p}<5 \%, * \mathrm{p}<10 \%$. 
Table 5: Earnings: 1993-2004 Cohorts, Initial Conditions and Persistence of Shock

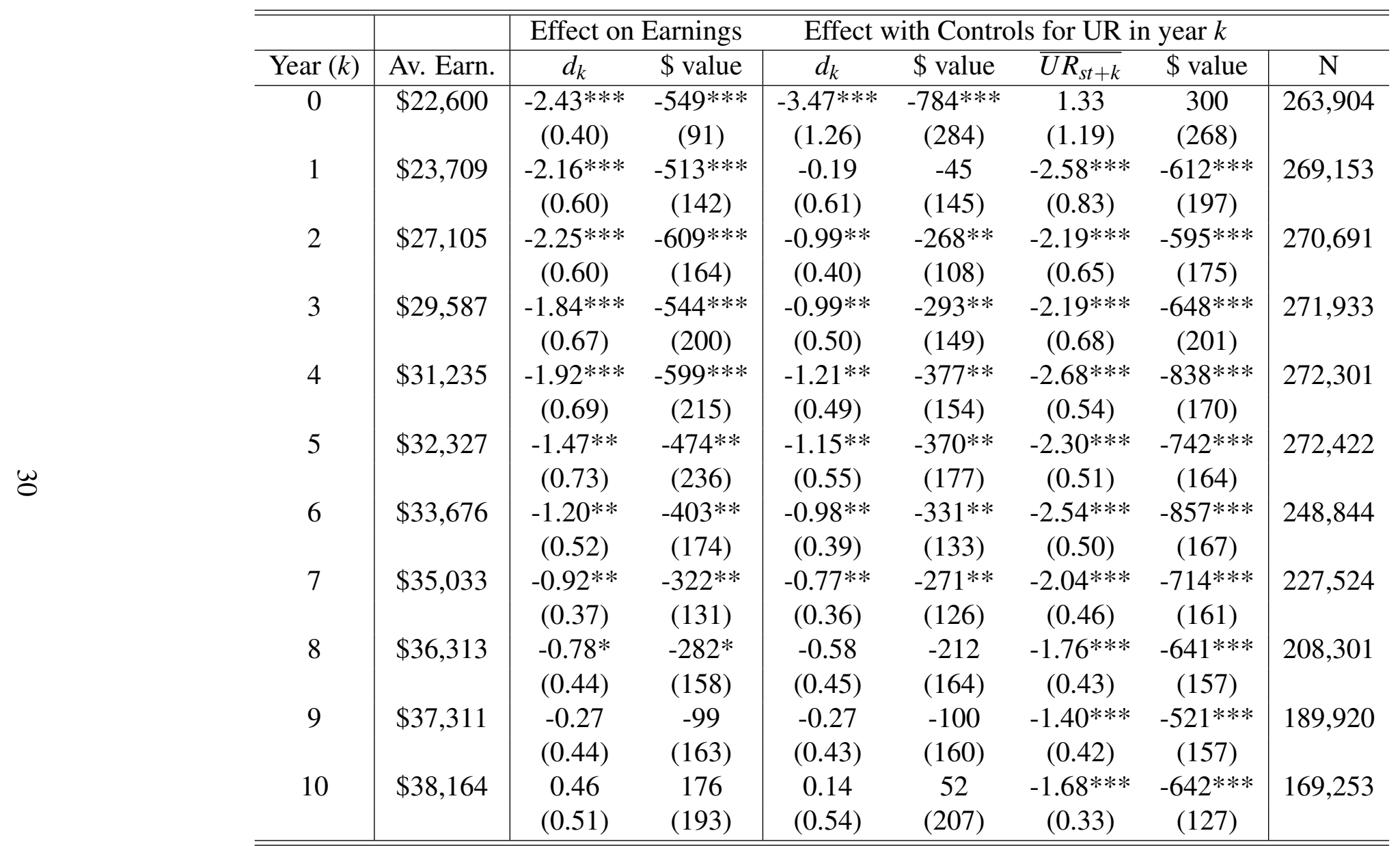

Notes: Table reports average earnings, $d_{k}$ from Equation 5, the effect of unemployment in the three months after the end of the initial enlistment contract on earnings at the $k$-horizon, and the dollar value of earnings losses. Sample composed of an unbalanced panel of all enlisted men who separate at the end of a first contract ending between 1993 and 2004 and do not use their GI Bill benefits; we correct for selection into reenlistment. Total earnings defined as SSA earnings plus untaxed military income. Estimates of the effect of initial conditions control for subsequent unemployment rates, $\overline{U R_{s t}+k}$. Real $2010 \$$ (CPI). s.e. clustered by state of enlistment. Significance levels: *** $\mathrm{p}<1 \%, * * \mathrm{p}<5 \%$, $* \mathrm{p}<10 \%$. 
Table 6: Mitigating Mechanisms

\begin{tabular}{cc|cc|cc|cc}
\hline \hline & \multicolumn{2}{|c}{$\rho=0.95$} & \multicolumn{2}{c}{$\rho=0.9$} & \multicolumn{2}{c}{$\rho=0.8$} \\
\hline \multicolumn{2}{c|}{$\$ y\left(U R_{s t}\right)$} & \multicolumn{3}{c}{$\$ 3677(0.78 \%)$} & $\$ 3101$ & $(1.31 \%)$ & \multicolumn{2}{c}{$\$ 2262(1.91 \%)$} \\
\hline & & WTP & $m$ & WTP & $m$ & WTP & $m$ \\
\hline$\beta / \gamma$ & 0.5 & $\$ 722$ & 0.80 & $\$ 676$ & 0.78 & $\$ 603$ & 0.73 \\
$(\approx \%$ wage, & 1.5 & $\$ 1443$ & 0.61 & $\$ 1352$ & 0.56 & $\$ 1207$ & 0.47 \\
next contract $)$ & 2 & $\$ 2886$ & 0.41 & $\$ 2029$ & 0.35 & $\$ 1810$ & 0.20 \\
& 2.5 & $\$ 3610$ & 0.02 & $\$ 2706$ & 0.13 & $\$ 2414$ & -0.07 \\
\hline \hline
\end{tabular}

Notes: Mitigating mechanism, $m$, appear in the model as the residual percentage of the PDV of earnings losses, $\Delta y(U R)$, left unexplained by the willingness-to-pay (WTP), so $m=1-\frac{W T P}{\Delta y\left(U R_{s t}\right)}$. Here, we quantify the share of earnings losses offset by mitigating mechanisms, under the range of plausible values of the discount rate and the ratio of regression parameters, $\beta / \gamma$. In the $\Delta y\left(U R_{s t}\right)$ row we report the PDV of earnings losses, and the implied drop in permanent income. Mitigating mechanisms account for between -33 and $80 \%$ of earnings losses, with our preferred estimates of $13-35 \%$ corresponding to $\rho=0.9$ and $\beta / \gamma$ between 1.5 and 2. 
Figure 1: Reenlistment Rises with State Unemployment and Bonus Offers, 1993-2009
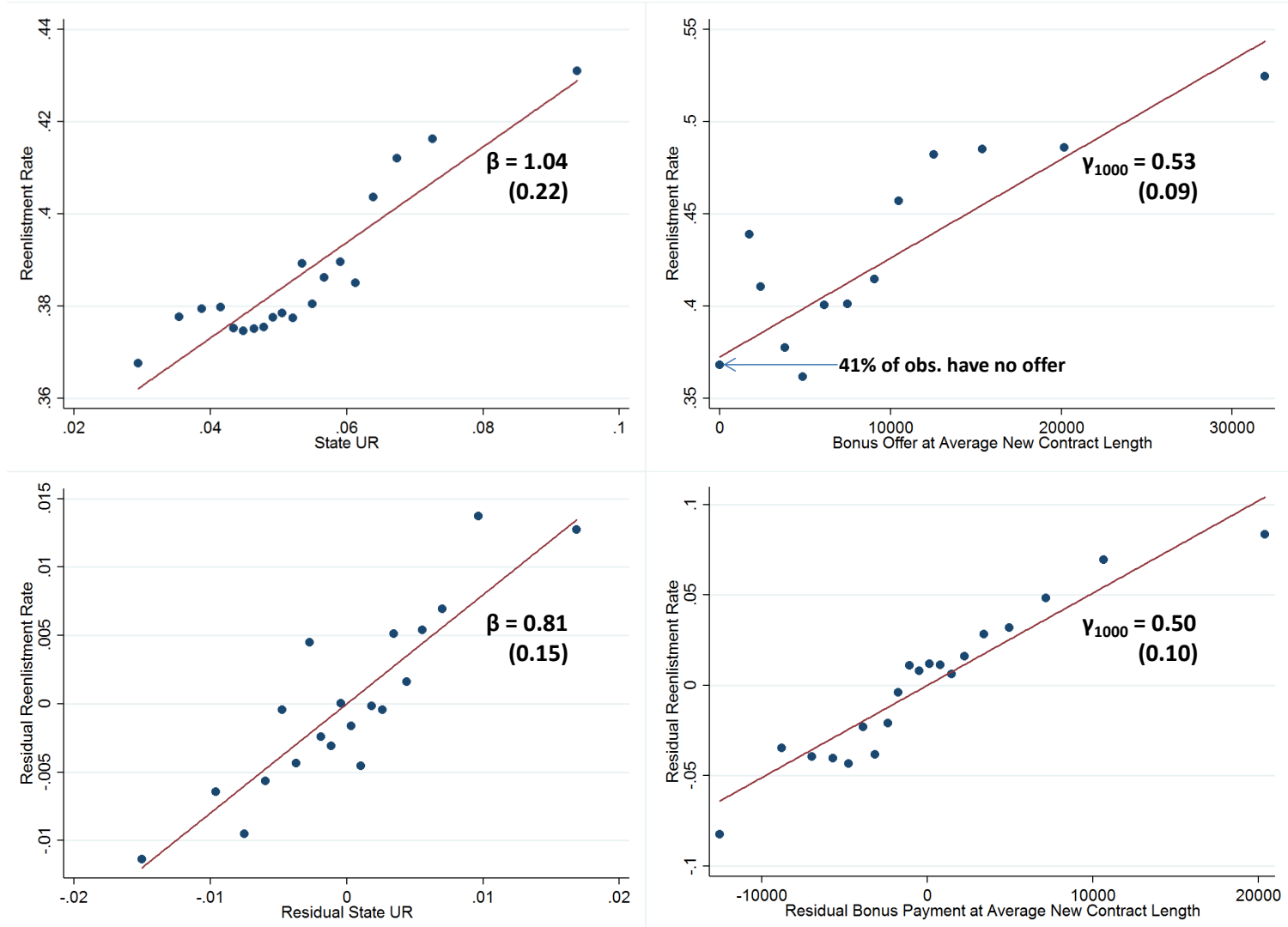

Notes: Figures plot the mean of dependent variable within 20 equally sized bins, except in the case of the top right figure, which combines the bottom 8 bins. The relative response $\left(\beta / \gamma_{1000}\right)$ is the trade-off (in 1000's of bonus dollars) for exit at different values of the state unemployment rate. The residual plots remove the effect of year of eligibility for discharge, state effects and the unemployment rate at enlistment. 
Figure 2: Effect of Unemployment on Earnings, Selection and Civilian Earnings, 1993-2009 Cohorts

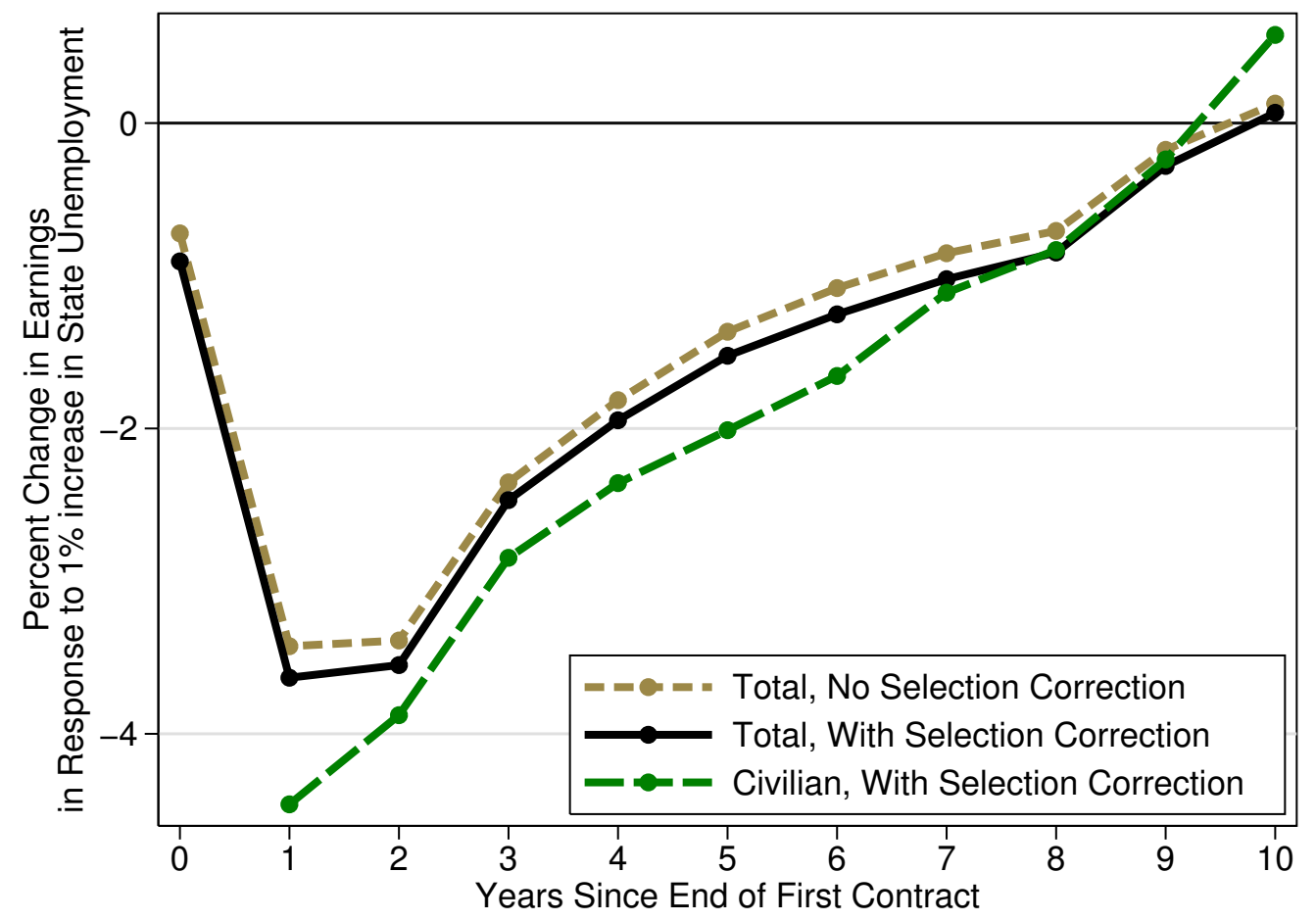

Notes: Figure plots coefficients from a regression of earnings $k$ years after the end of the initial enlistment contract on state unemployment in the 3 months following the end of the contract for our primary specification (Total, with Selection Correction) and 2 alternative specifications: the first alternative specification drops the selection correction; the second alternative specification plots the effect on civilian earnings, defined as SSA earnings minus military income. Civilian earnings show a large proportional effect in year 0 , however, this comes on a small base in income; we omit the year 0 civilian estimate from the figure to maintain scale. See text for additional details on regression specification, and Table 4 for average earnings, dollar value of losses, and standard errors. 
Figure 3: Effect of Unemployment on Earnings and Persistence of Initial Conditions, 1993-2004 Cohorts

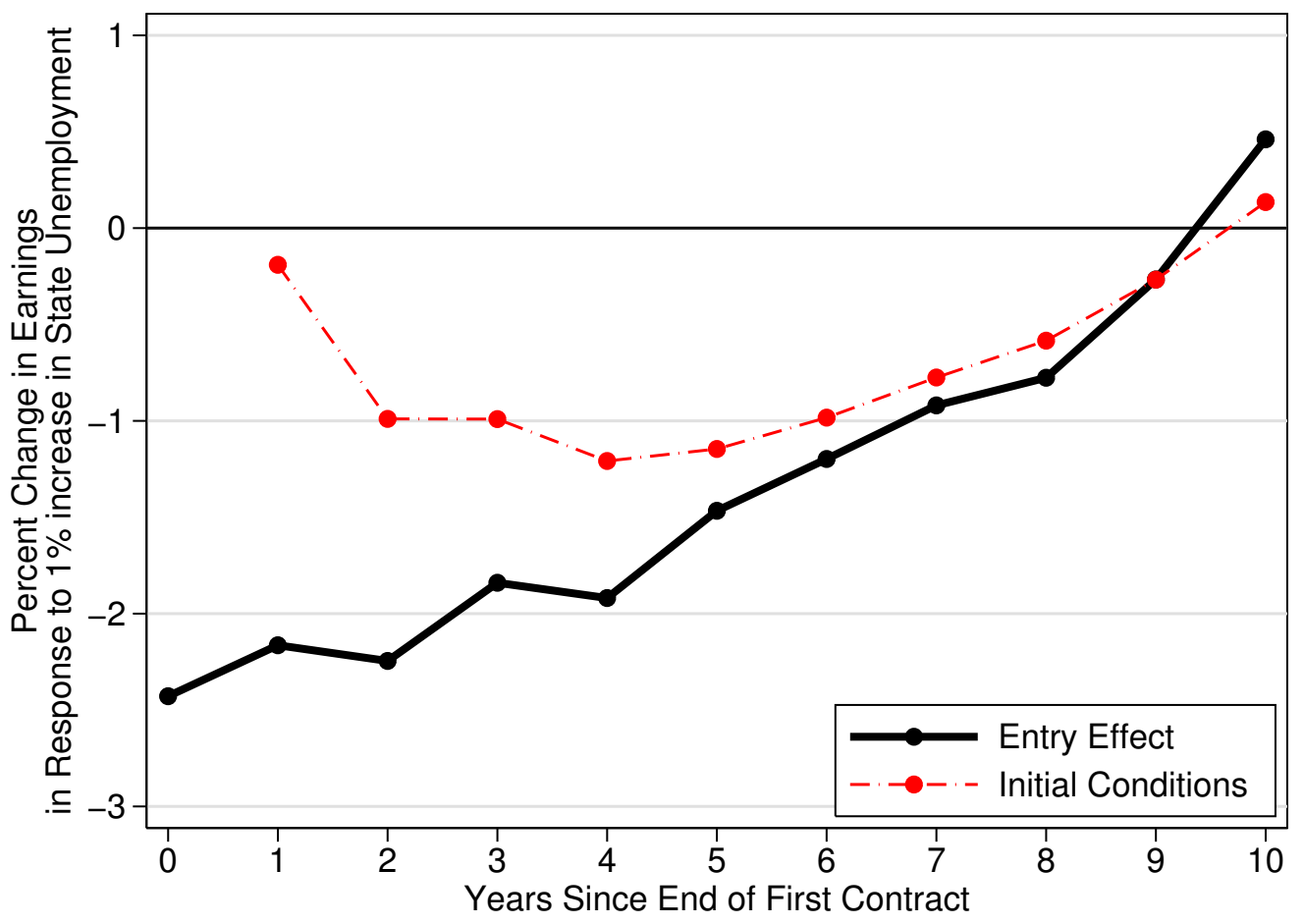

Notes: Figure plots coefficients from a regression of earnings $k$ years after the end of the first contract on state unemployment in the 3 months following the end of the contract; regression includes year fixed effects. Initial conditions estimates control for year $k$ unemployment rates to account for the serial correlation between $U R_{s t}$ and subsequent unemployment rates. We correct for selection and drop those who use the college benefit; panel is balanced through year 5. Regression coefficients and standard errors reported in Table 4 . 


\section{FOR ONLINE PUBLICATION Appendix Tables and Figures}

\section{A1 Instrumental Variable Estimates of the Reenlistment Model}

The reenlistment model uses variation in bonuses across occupations to estimate the responsiveness of reenlistment to financial incentives. Variation in the bonus may arise for either demand or supply-related reasons. Ideally, we would like to isolate pure demand-side variation, in which the military changes bonuses in response to (exogenous) shocks to the target-level of enlistment in an career field, holding constant working conditions, civilian labor market opportunities and other aspects of broadly-defined compensation. The 1993-2004 era presents a promising era for this type of variation, as the structure of the military changed a great deal in the years following the Cold War and Gulf War of 1990-1991, and again in the initial stages of the Afghanistan and Iraq Wars (initially predicted to be short engagements). In addition, the focus on first-term enlistment limits the potential for large-scale changes in civilian labor market opportunities (i.e. career-field-specific changes not captured by the year effects). Consistent with the choice of era and sample, we found the estimates to be insensitive to a range of controls for the most likely confounds (such as exposure to deployment and hostile fire) and insensitive to the inclusion of the average characteristics of servicemembers who do reenlist (which would be the case if the military changes reenlistment eligibility standards).

To investigate further the potential endogeneity of bonuses, we estimated an instrumental variables (IV) model based on career field-specific shocks to military labor demand. To isolate labor demand movements, we use the flow of new recruits within a career field. This flow more closely reflects a pure measure of labor demand within the career field, as it is unconstrained by previous assignments of servicemembers to occupations, and unrelated to reenlistment choices (the outcome in the model). Specifically, we instrument the bonus with the flow of new recruits to the career field in the reenlistment year $t, L_{o t}$, conditional on the flow at the time of entry, $L_{o t-j}{ }^{24}$ The first-stage equation in the IV model is:

$$
B_{i o t}=\psi_{o}+\sigma_{j(i) t}+\phi L_{o t}+\pi L_{o t-j(i)}+\tau B_{i o t-j(i)}+\xi \mathbf{X}_{i o t}+v_{i o t},
$$

where $\psi_{o}$ indicates military career field, $\sigma_{j(i) t}$ indicates year of eligibility for discharge, $L_{o t}$ is the labor demand shock, the size of the entering class in the $o$ career field, $L_{o t-j(i)}$ and $b_{i o t-j}$ control

\footnotetext{
${ }^{24}$ To the best of our knowledge, this is the first published paper to employ this strategy. We know of at least one internal analysis at RAND that explored a similar IV strategy using occupation-specific staffing authorizations, but was never released. Results in that study were similar to the results reported here.
} 
for the size of the career field cohort and bonus at entry, and $\mathbf{X}_{\text {iost }}$ contains the full set of controls required to maintain consistency with the previous analysis. Our estimates will capture the causal effect of bonus payments on reenlistment under the assumption that the same underlying careerfield demand shock drives both the target level of new recruits in the field and the bonus level for re-enlistees, and that the bonus represents the military's sole control variable in reenlistment. ${ }^{25}$ As the military desires a stable tenure pyramid and does not permit mid-career entry, the flow of new recruits into career fields should also reflect an increased demand for higher tenured workers of the same type that cannot be met except through reenlistment. New recruits do not appear to substitute for higher tenure servicemembers, as the size of the entry cohort does not predict speed of promotion.

The primary threat to the validity of this instrumental variables strategy arises due to the use of alternative reenlistment controls in conjunction with, or in place of bonuses. For example, the military has historically used changes to reenlistment windows (the window before the end of the first contract in which one can sign a new contract), review boards (screening of personnel files), bonus caps (setting a maximum contract length eligible for bonus) and other measures to meet its reenlistment goals. These measures are particularly common in periods of declining demand, when the bonus for many occupations reaches a lower bound of zero. Alternative control variables (in our model, the extent to which the military can directly affect working conditions $\mu_{o t}$ ) will mean that using the measures of military labor demand as an instrument violates the exclusion restriction. Empirically, this seems to be the case; however, we argue that we can sign this bias, and provide some guidance on its magnitude. Specifically, these alternative measures can be assumed to positively correlate with the bonus, as they serve essentially the same purpose in controlling reenlistment. As well, the upward bias will be approximately proportional to the percentage of reenlistments paid a bonus, on the assumption that the military switches to alternative measures of reenlistment control when the bonus falls to zero.

Table A3 contains the results of the IV estimation. The upper panel reports the first-stage results, including Kleibergen-Paap (heteroskedasticity-robust) F-statistics for the significance of the excluded regressor. In each case, the first stage F-statistics exceeds 10, so the size of the entry cohort in the career field has significant predictive power over the bonus offer made to those up for reenlistment. We do not report results for the longer sample (1993-2009), as the first-stage did not approach the rule of thumb F-statistic of 10 . This likely reflects recruitment and reenlistment shortfalls that occurred in 2005-2008.

\footnotetext{
${ }^{25}$ We also assume that military occupation-specific demand is uncorrelated with local labor market conditions. We test this by regressing the the bonus and the recruitment flow on unemployment rates, finding no significant effect.
} 
The lower panel applies the IV model to the 1993-2004 sample. Instrumenting the bonus increases the reenlistment response by a factor of approximately 1.5 to 3 compared to the OLS estimates, implying a corresponding reduction in the value of unemployment. Note that the unemployment rate coefficient $(\beta)$ remains robust across the OLS and IV specifications: the gap between the OLS and IV estimates does not arise from the avoidance behavior (higher reenlistment in response to arises from the response to pay), but rather from the price of this avoidance behavior (the increase in reenlistment in response to bonus pay). The coefficient in the first column of 0.93 means that a $10 \%$ increase in pay results in a $9.3 \%$ increase in reenlistment. Moving across the columns, we cannot reject the equality of bonus coefficients in the 1993-2004 sample period, although the estimates are larger when we control for (average) in-service experiences and smaller for those with longer initial contracts. Off a base $38 \%$ reenlistment rate, these point estimates imply an elasticity between 2.5 and 3 in the earlier sample period. This elasticity is on the higher end or above what has been found in previous studies of reenlistment. Despite this increase, the IV estimates allow us to test and reject the presence of full insurance against movements in end-of-contract unemployment in all specifications.

We have argued the IV estimates will be biased upwards by the presence of other reenlistment measures, but how large is this bias, and can it account for the difference in the OLS and IV? Suggestive evidence appears in Figure 1. When we residualize the bonus, we find no smaller effect of a predicted negative bonus on reenlistment, implying that the military simply switches to other reenlistment levers when the bonus should be negative. Following to this logic, we assume the percentage of soldiers offered a bonus reflects the share of reenlistment control provided by the bonus. In the 1993-2004 period, 62\% of occupations are offered a bonus. To correct our IV estimates for this bias, we simply multiply our estimates of the (instrumented) bonus response by 0.62 , and report this value at the bottom of Table A3. After this adjustment, our estimates of $\beta / \gamma$ lie between 1.1 and 2.5, with most values between 1.5 and 2. Thus, our IV results support the OLS results, once we account for the channels aside from the bonus through which the military can affect reenlistment.

\section{A2 Behavioral Responses to Unemployment and Effect on Estimates}

In this appendix section, we describe several analyses of behavioral responses to unemployment at the end of the first contract, with the goal of relating these changes to the results presented in the main text. We also discuss measurement issues in the primary variables. These calculations are referenced in Section 3.1 .

We require alternative data sources for some of this analysis, as we cannot observe outcomes 
beyond earnings and college benefit usage in the administrative data. First, we present results on the effect of unemployment at separation, which may not occur in the month the initial contract ends, even for those who do not reenlist. Next, we summarize our analysis of young veterans' migration. Finally, we detail the response of college enrollment and benefits usage. In each case, we find evidence that our estimates represent lower bounds on the true effect of interest. In sum, effects of unemployment in the state of residence at the precise time of separation appear to be $24 \%$ to $32 \%$ larger than the effect of unemployment in the state of enlistment at the end of contract.

\section{A2.1 Timing of Separation}

Servicemembers have the opportunity to seek early discharge, and short extensions that would not meet our definition of reenlistment. Appendix Figure A5 displays the c.d.f. of month of separation for non-reenlisting servicemembers with different initial contract lengths. The figure is truncated at 100 months, however, it is clear that the separation hazard is nearly zero at this point. Removing the truncation would reveal that almost all separations of those who we classify as not reenlisting occurs within the 100-month window.

For a policy maker interested in the welfare of young veterans, the more relevant effect would be that of the effect of unemployment at the actual time of discharge. Using the end-of-contract unemployment rate effectively results in a mis-measured separation unemployment rate, correction for which requires an increase in the coefficient by the inverse of the linear prediction of the separation rate by the end of contract unemployment rate, the Wald estimator. A regression in the framework from above of the unemployment rate at actual separation on the rate at the end of the first contract reveals a coefficient of 0.845 in 1993-2004, and 0.843 in 1993-2009; the relationship between the end of contract and separation date appears to be relatively stable over time. In either case, the inverse of the regression coefficient implies an increase of 17-18\% would result from the use of the end of contract rate as an instrument for the separation rate, with little loss of precision. While we continue to use the end of contract rate throughout the paper, estimated effects can be scaled by this factor to reach the effect at separation.

\section{A2.2 Migration}

Veterans are a highly mobile population, and when we correct for the resulting mis-measurement of the relevant unemployment rate, the earnings effects above are magnified by as much as $20 \%$.

There are two elements of the migration margin that may enter our calculation. First, some veterans will migrate over the course of their first contract, resulting in measurement error from the use of the home-state unemployment rate; this occurs independent of the period. Second, 
veterans may respond to changes in economic conditions by migrating at higher or lower rates. Data is a serious challenge, because we require a panel that surveys veterans both before and after service. We draw evidence from the Current Population Survey, American Community Survey and 1979 and 1997 National Longitudinal Surveys of Youth. We summarize the analysis here, the details of which are available upon request from the authors.

Volunteer-era veterans in the Census and ACS migrate at higher rates than non-veterans, measured both as probability of residing in their state of birth, and the probability of recent migration. We estimate that $10-15 \%$ of veterans do not return to their home state. If economic conditions in the destination state are unrelated to the source state, we should adjust our estimates upwards by a slightly smaller amount (11-17\%) than we did to account for the timing of separation. Correcting for the directedness of migration using the 2006-2011 estimate of Yagan (2013) leads us to reduce this to $8-13 \%, 26$

While an adjustment for average migration translates our estimates into the policy-relevant effect for transitioning veterans, we have also investigated changes in migration over time. We do not have data that allows us to estimate changes over time with the precision required to incorporate these estimates in our analysis; here, we summarize broad patterns that emerged in our analysis and discuss potential biases. The most important finding is that veterans' migration rates have fallen over the last 20 years, paralleling declines among non-veterans. These declining migration rates could partially explain the larger effects (both the response of earnings to home-state unemployment and the response of reenlistment to home-state unemployment) when we extend the sample to the later period; quantifying this effect leads to the reduction of the above adjustment from 8$13 \%$ down to $6-12 \%$ in the longer sample. Using the NLSY79, we test for differential migration responses in response to unemployment. This would be of particular concern if unemployment makes young veterans more likely to stay in their state of enlistment, for example, because unemployment insurance for veterans (UCX) is available in the state of enlistment. Although we cannot use the same rich covariate structure in the smaller sample, what evidence we find suggests there may be an increase in the probability of migration in response to unemployment. Correcting for this pattern of differential migration would increase our estimates further; we would be estimating a treatment-on-the-treated (ToT) effect. Given the paucity of data, we prefer to stick to the single correction for the average level of migration.

Finally, some portion of the persistence of the shock likely reflects migration away from the

\footnotetext{
${ }^{26}$ Yagan (2013) uses IRS tax records to document the response of migration to local labor market shocks in 20012011 , and finds that destination states received $25 \%$ of the shock received by source states, the estimate of directedness in this period. Note that this estimate uses e-pop instead of the unemployment rate; these two measures of business cycle conditions generally move in tandem.
} 
state of enlistment in the years following discharge. In other words, the initial unemployment rate loses much of its relevance to labor market outcomes as young veterans flow out of their state of enlistment over the years following discharge. Somewhere between 8 and $14 \%$ of veterans ages 22-30 in the ACS report migrating between states in the preceding year, suggesting this explains a reasonable portion of the decay in the effect. To the degree that this reflects differential migration in response to labor market conditions, this migration may permit young veterans to improve the outcome on the earnings dimension, while suffering costs on other dimensions. As we lack detailed evidence on these effects, and believe our current estimates reflect the primary economically- and

policy-relevant effects of interest, we leave these questions regarding veterans migratory behavior for future work.

\section{A2.3 Education Benefits}

The final margin of behavioral response that plays a role in our analysis is the use of GI Bill benefits. We have no quantitative estimate of the bias arising from selection into benefit usage, but the evidence suggests it is small.

GI Bill benefits pay up to 36 months of tuition and fees, materials, and a monthly stipend to veterans who enroll in degree-granting programs within 10 years of separation. These benefits are not taxed, and will not show up in the SSA or military earnings. College benefit usage during the 1991-2005 period has been analyzed by Simon et al. (2010), who find that benefit usage rises during times of national unemployment. In the main text, we show that estimated earnings responses do not change when we drop those who use their college benefits. The response of earnings for those who do not use their college benefits closely mirrors the average effect in the population, suggesting differential use of the benefits over the business cycle does not affect average earnings outcomes. Estimates for the 1993-2004 cohorts (not shown) look similar, with slightly larger losses for college attendees in the first two years. When we analyze the response of college benefit usage to state unemployment in our framework we find smaller responses than Simon et al. (2010) (who analyze national unemployment), with no effect on longer periods of usage. We take these facts as suggestive evidence that GI Bill benefits offer, at best, very minor protection from local economic conditions for the average service member. We hope to explore GI Bill benefit usage further in future work, however, its role as insurance against unemployment shocks does not appear important enough to affect our estimates for the population of young veterans.

The evidence in this appendix section allows the translation of the estimated effects into the relevant effects for the population of young veterans. Increasing the estimates by $30 \%$ results in earnings effects exceeding $4.5 \%$ in year 1 of the primary specification, and as we believe there 
are additional sources of measurement error in the estimation, there is scope for losses exceeding $5 \%$ of earnings. In the remaining analysis, however, we will set aside these adjustments and use the end-of-contract rate in the state of enlistment. The literature on college graduates and displaced workers generally makes no adjustment for the measurement of the unemployment rate, and we would like to have these estimates to serve as baselines for our results. The unadjusted unemployment rate has intuitive and economic appeal; as discussed in the introduction, long-term contracts play a large role in modern theories of business cycles, and this allows us to connect our estimates to this literature. With this in mind, the linearity of the models will allow the reader to apply these corrections to the estimates in the main text.

\section{A3 Compensated Labor Supply Elasticity Under Rationing}

One possible model which would allow the translation of earnings losses to welfare losses would be to use estimated labor supply elasticities to map the change in earnings to a compensating differential. The welfare losses estimated using this strategy would then depend on the labor supply elasticity in the calculation. In our case, we have both the change in earnings and required compensation, so we can reverse this process to estimate an implied labor supply elasticity.

In the absence of data on post-service wages and hours worked, we must make some simplifications in order to perform the caculation. One possibility is to follow the assumption of Ashenfelter (1980), and assume that hours are rationed at a constant wage. Ashenfelter derives the share of lost earnings, $C^{*}$, required to compensate a worker who is prevented by rationing from the sale of a share, $D_{1}$, of their optimal labor supply:

$$
C^{*} \approx(1 / 2) D_{1} / e_{11}
$$

where $e_{11}$ is the compensated elasticity of labor supply. This is a normal triangle estimator, where the proportional welfare loss rises with the size of the distortion. 27

In our setting, we have estimated the average $C^{*}$, which is the share of earnings that is not offset by mitigating mechanisms, $1-m$. To recover $D_{1}$ requires a little more thought. According to this model, the worker supplies an optimal amount of labor to the market unless constrained; there is never an over-supply of labor. This suggests we take some sort of maximum earnings, and use the average earnings below this maximum as the average $D_{1}$. This is impractical, given worker heterogeneity and data constraints. Another alternative is to use the unemployment rate changes literally: a one percentage point unemployment rate change means that $1 \%$ of hours go unsold.

\footnotetext{
$\sqrt[27]{\text { Ashenfelter }}(1980)$ extends the analysis to include additional household members, hence the subscripts.
} 
From our estimation in Table 6, the percentage of lost lifetime hours/earnings (at $\rho=0.9)$ are $1.31 \%$. Using this value as $D_{1}$ gives a compensated elasticity of labor supply of 0.01 for $m=13 \%$ and a compensated elasticity of 0.02 for $m=35 \%$. This estimate is low, and in fact, is quite close to zero. The calculation appears to be relatively insensitive to the choice of $D_{1}$ or the discount factor in the implementation of the model, due to the estimates of $m$ far from 1. Intuitively, if workers require large payments to make relatively small deviations from their optimal labor supply choice, then they must have inelastic preferences. A compensated labor supply elasticity near zero is consistent with the evidence for labor supply elasticities of prime-age males discussed in Saez et al. (2012). 
Table A1: Summary Statistics

\begin{tabular}{lcccc|cccc}
\hline \hline & \multicolumn{3}{c}{ All Enlisted Men: $1993-2009$} & \multicolumn{6}{c}{ Young Veterans: 1993-2009 } \\
\hline & Mean & SD & p10 & p90 & Mean & SD & p10 & p90 \\
\hline Eligible Age & 24.06 & 2.39 & 22 & 27 & 23.92 & 2.26 & 22 & 27 \\
More than HS & 0.09 & 0.29 & & & 0.09 & 0.28 & & \\
Single at Entry & 0.88 & 0.32 & & & 0.90 & 0.30 & & \\
AFQT Percentile & 58.94 & 17.89 & 35 & 84 & 58.89 & 17.92 & 35 & 84 \\
White & 0.67 & 0.47 & & & 0.70 & 0.46 & & \\
Black & 0.16 & 0.37 & & & 0.14 & 0.35 & & \\
Hispanic & 0.10 & 0.30 & & & 0.10 & 0.30 & & \\
Initial Term & 4.03 & 0.69 & & 4.00 & 0.66 & & \\
$\mathrm{~N}$ & $1,098,377$ & & \multicolumn{7}{|c}{673,260} \\
\hline \hline
\end{tabular}

Notes: Descriptive statistics for All Enlisted Men with initial enlistment contracts ending between 1993 and 2009, and the subgroup of Young Veterans, defined as enlisted men who do not reenlist by the end of the first contract. AFQT, education and marital status measured at entry. 
Table A2: Career Fields and Occupation Examples

\begin{tabular}{l|c|l}
\hline \hline Service/Career Field & Abbr. & 3-digit Occupations \\
\hline Army & & \\
\hline Infantry & 11 & Infantryman (11B), Mortarman (11C) \\
Aviation & 15 & Air Traffic Control Operator (15Q), Aircraft Electrician (15F) \\
Signal Corps & 25 & Radio Operator (25C), Cyber Network Defender (25D) \\
Adjunct General & 42 & Human Resources Specialist (42A), Musician (42R) \\
\hline \hline Navy & & \\
\hline Naval Aircrewman & AW & Aircrewman Helicopter (AWS), Aircrewman Avionics (AWV) \\
Steelworker & SW & no 3-digit sub-classifications \\
Culinary Specialist & CS & Culinary Specialist-Submarine (CSS) \\
Cryptologic Technician & CT & Maintenance (CTM), Collection (CTR) \\
\hline \hline Marines & & \\
\hline Personnel and Admin. & 01 & Personnel Clerk (0121), Career Retention Specialist (0143) \\
Infantry & 03 & Rifleman (0311), Mortarman (0341) \\
Utilities & 11 & Electrician (1141), Refrigeration and AC Technician (1161) \\
Ground Ordinance Maint. & 21 & Small Arms Repair (2111), Machinist (2161) \\
\hline \hline Air Force & & \\
\hline Aircrew Operations & 1A & Aircraft Loadmaster (1A2X1), Flight Attendant (1A6X1) \\
Command and Control & 1C & Air Traffic Control (1C1X1), Airfield Management (1C7X1) \\
Aerospace Maint. & 2A & Aircraft Fuel Sys. (2A6X4), Aircraft Struct. Maint. (2A7X2) \\
Civil Engineering & 3E & HVAC and Refrigeration (3E1X1), Fire Protection (3E7X1) \\
\hline \multicolumn{2}{|l}{}
\end{tabular}


Table A3: Effect of Bonus and Unemployment Rate on Reenlistment: IV Model, 1993-2004

\begin{tabular}{lcccccccc}
\hline & OLS & IV & IV & IV & IV & IV & IV & IV \\
\hline lnEntryCohort & & All & All & All & $j \geq 4$ & $j \geq 4$ & $N_{o t}>15$ & Late \\
& & $0.010^{* * *}$ & $0.010^{* * *}$ & $0.010^{* * *}$ & $0.011^{* * *}$ & $0.012^{* * *}$ & $0.010^{* * *}$ & $0.010^{* * *}$ \\
& & $(0.002)$ & $(0.003)$ & $(0.002)$ & $(0.004)$ & $(0.003)$ & $(0.003)$ & $(0.003)$ \\
\hline 1st stage F-stat & & 12.60 & 12.92 & 13.44 & 10.56 & 10.62 & 12.74 & 13.25 \\
\hline & OLS & IV & IV & IV & IV & IV & IV & IV \\
\hline Bonus $(\gamma)$ & $0.37^{* * *}$ & $0.93^{* * *}$ & $0.88^{* * *}$ & $1.16^{* * *}$ & $0.66^{* * *}$ & $0.94^{* * *}$ & $0.85^{* * *}$ & $0.80^{* * *}$ \\
& $(0.04)$ & $(0.30)$ & $(0.29)$ & $(0.34)$ & $(0.27)$ & $(0.31)$ & $(0.29)$ & $(0.29)$ \\
UR $(\beta)$ & $0.85^{* * *}$ & $0.84^{* * *}$ & $0.84^{* * *}$ & $0.83^{* * *}$ & $1.06^{* * *}$ & $1.06^{* * *}$ & $0.90^{* * *}$ & $0.95^{* * *}$ \\
& $(0.19)$ & $(0.18)$ & $(0.18)$ & $(0.17)$ & $(0.18)$ & $(0.17)$ & $(0.17)$ & $(0.20)$ \\
\hline$\beta / \gamma$ & $2.27^{* * *}$ & $0.91^{* *}$ & $0.96^{* *}$ & $0.71^{* *}$ & $1.62^{* *}$ & $1.13^{* * *}$ & $1.06^{* *}$ & $1.17^{* *}$ \\
& $(0.63)$ & $(0.37)$ & $(0.40)$ & $(0.27)$ & $(0.71)$ & $(0.42)$ & $(0.45)$ & $(0.51)$ \\
\hline$\beta /(0.62 \gamma)$ & & 1.44 & 1.51 & 1.14 & 2.54 & 1.78 & 1.67 & 1.88 \\
\hline Mean AFQT, BMI & $\mathrm{x}$ & & $\mathrm{x}$ & $\mathrm{x}$ & $\mathrm{x}$ & $\mathrm{x}$ & $\mathrm{x}$ & $\mathrm{x}$ \\
In-service $X_{i}$ & & & & $\mathrm{x}$ & & $\mathrm{x}$ & & 294 \\
\hline Career Fields & 323 & 303 & 303 & 291 & 299 & 281 & 212 & 294 \\
$\mathrm{~N}$ & 632,261 & 625,755 & 625,755 & 622,855 & 491,893 & 490,162 & 619,210 & 562,144 \\
\hline \hline
\end{tabular}

Notes: Table reports results of IV regressions of reenlistment on bonus incentives and state unemployment rates with a rich set of controls (see text for details). The ratio of regression coefficients, $\beta / \gamma$, represents the willingness-to-pay (as a percentage of earnings on the next contract) for reenlistment in response to changes in home state economic conditions. Sample composed of all enlisted servicemembers at end of first contract between 1993 and 2004 with other sample restrictions noted in column headers: all contracts, initial contracts of at least 4 years $(j \geq 4 \mathrm{y})$, dropping small occupations $\left(N_{o t} \geq 15\right)$ and restricting to reenlistments occurring in the last year of the contract (Late). s.e. clustered by career field and state of enlistment. Kleibergen-Paap F-statistics reported for 1st stage. Significance levels: $* * * \mathrm{p}<1 \%, * * \mathrm{p}<5 \%$, $* \mathrm{p}<10 \%$. 
Figure A1: Bonuses and Reenlistment

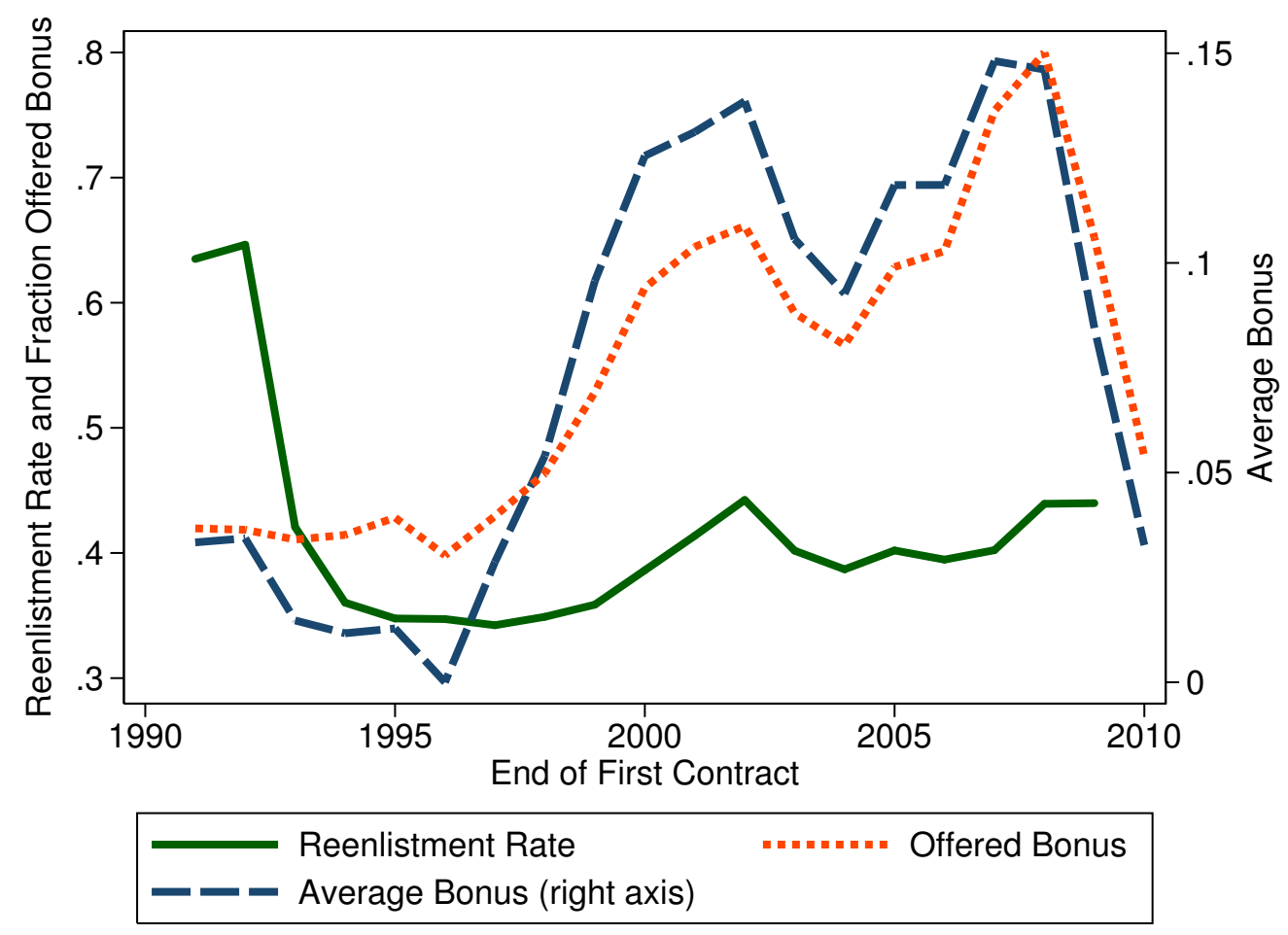

Notes: Bonuses grew in importance over the 1991-2010 period, increasing in economic expansions (particularly the late 1990s) and wars, and falling during military drawdowns (for example, in the mid-1990s and at the end of the sample) and recessions. Reenlistment shortfalls (relative to goals) occurred in 2005-2007. Sample composed of all enlisted servicemembers at end of first contract. The bonus formula $=$ months reenlisted $\left(T^{*}\right)$ x bonus multiplier $\left(b_{o t}\right)$ x monthly basic salary $\left(y_{i t}^{m i l}\right)$. 
Figure A2: Effect of Unemployment on Earnings, By College Benefit Usage, 1993-2009 Cohorts

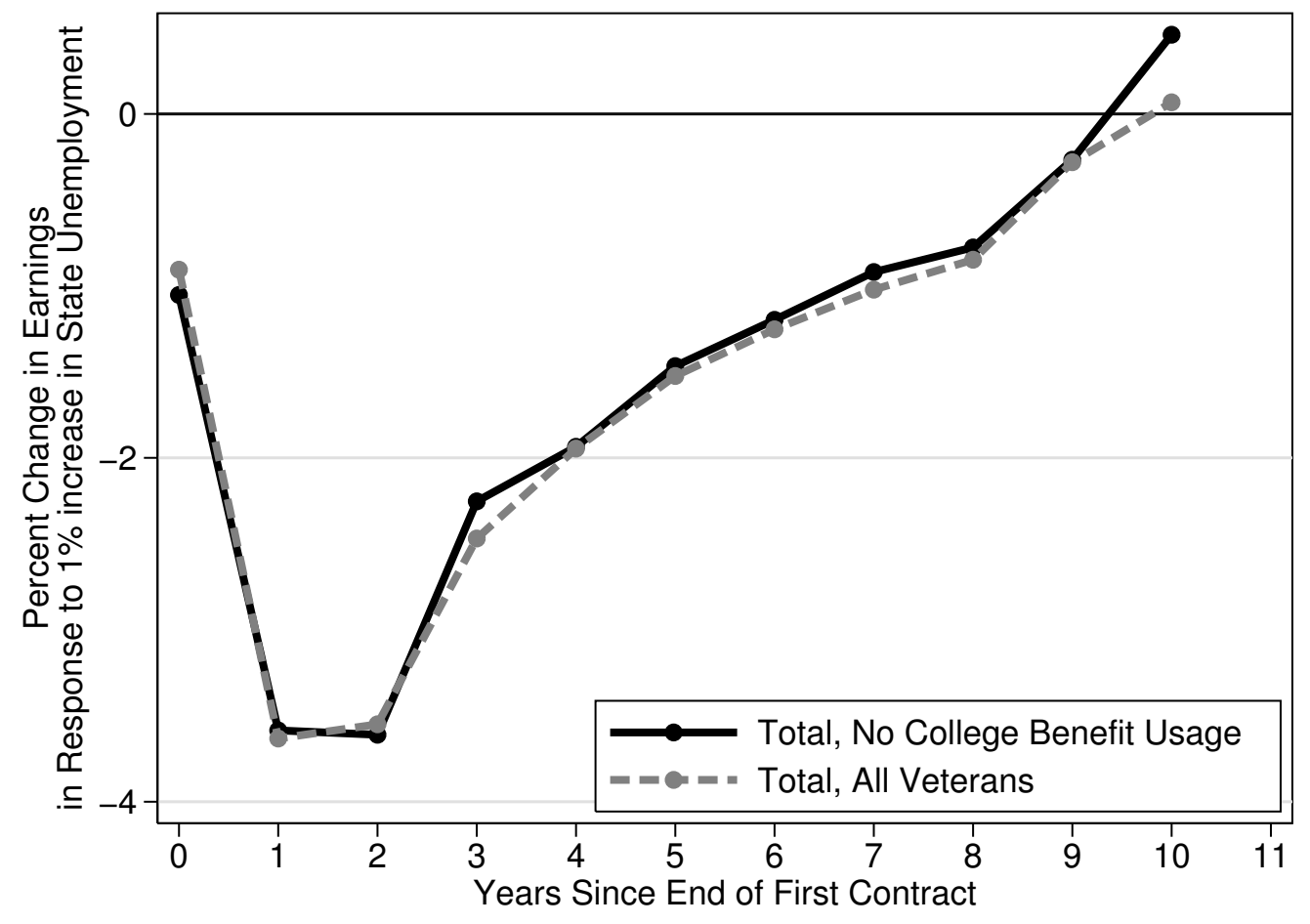

Notes: Figure plots the $\delta_{k}$ regression coefficients separately for all young veterans and those who do not use their college benefits. Dropping those who use their college benefits has little to no effect on our estimates. 
Figure A3: Effect of Unemployment on Earnings by Period, 1992-2009 Cohorts

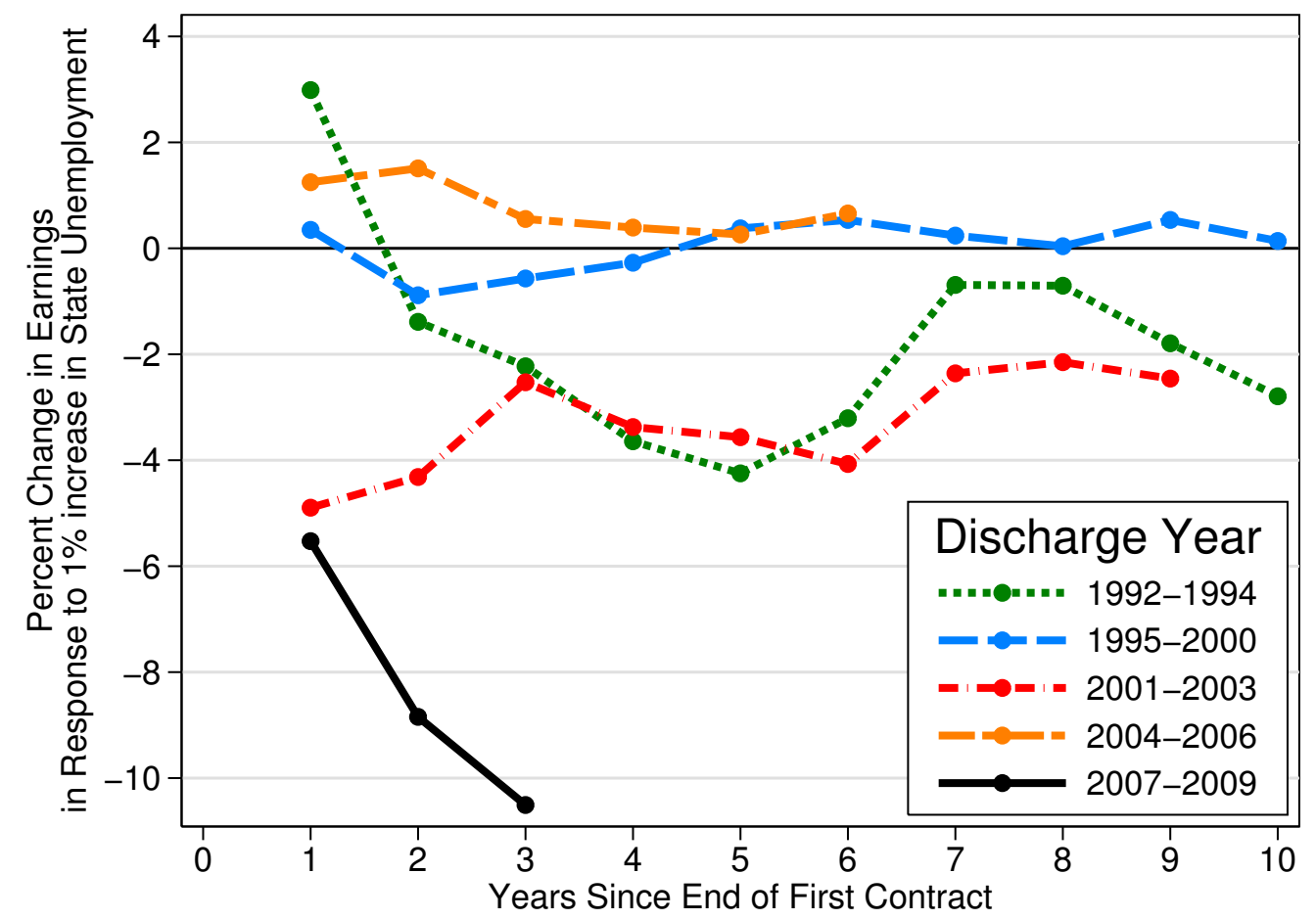

Notes: Figure plots coefficients from a regression of earnings $k$ years after the end of the initial enlistment contract on state unemployment in the 3 months following the end of the contract; regression includes year fixed effects. Discharge years 1992-1994, 2001-2003 and 2007-2009 approximately correspond to periods of national recessions. Unbalanced panels. We correct for selection and drop those who use the college benefit. 
Figure A4: Length of New Contract

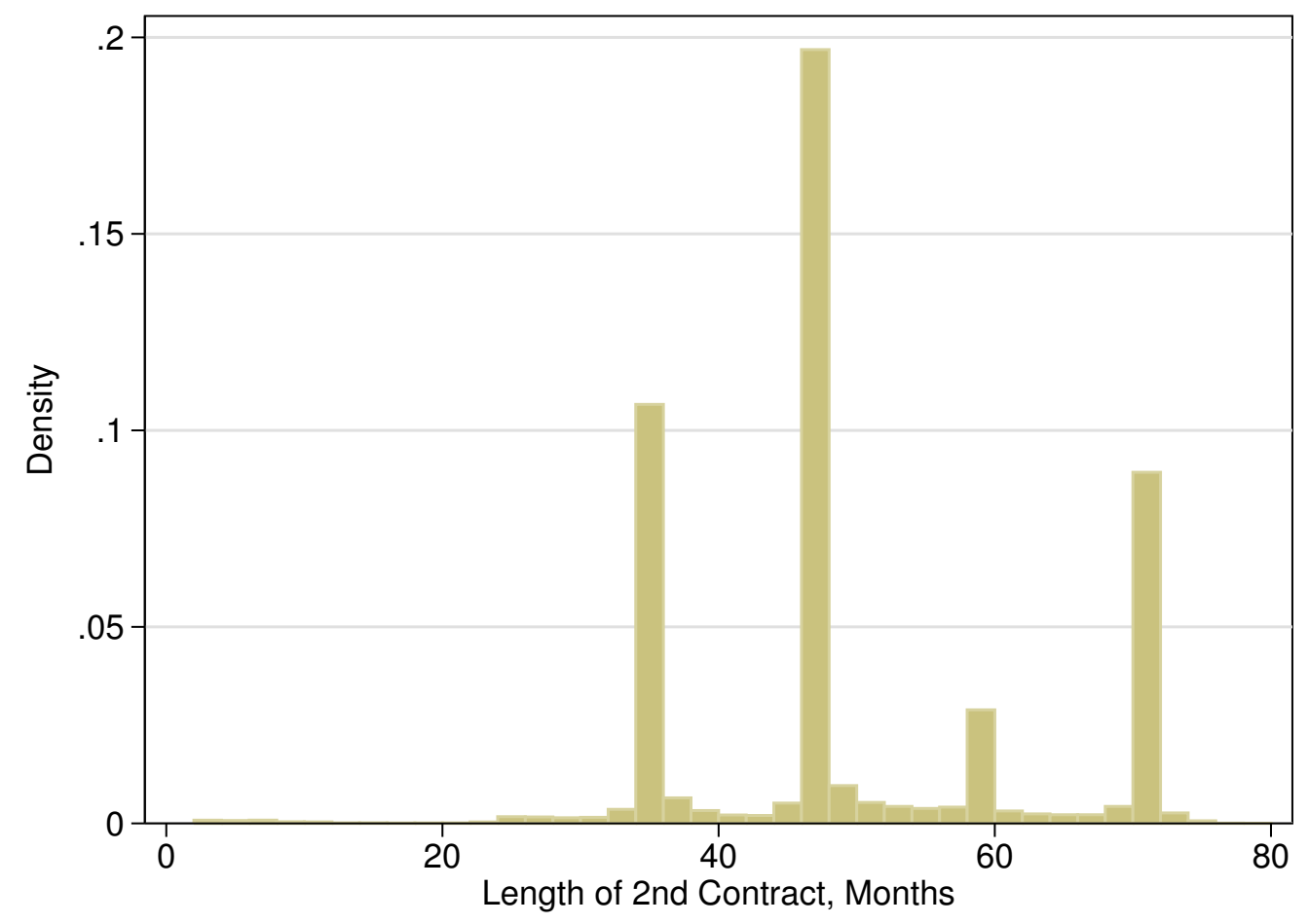

Notes: Sample composed of all enlisted servicemembers who do not separate within three months following the end of their first contract. Two-month bins. In our empirical specifications, we define reenlistment as an increase in months of service committed of 24 or more months within three months of the end of the first contract. As can be seen, this captures virtually all second contracts. 
Figure A5: Months of Service, No Reenlistment by End of First Contract

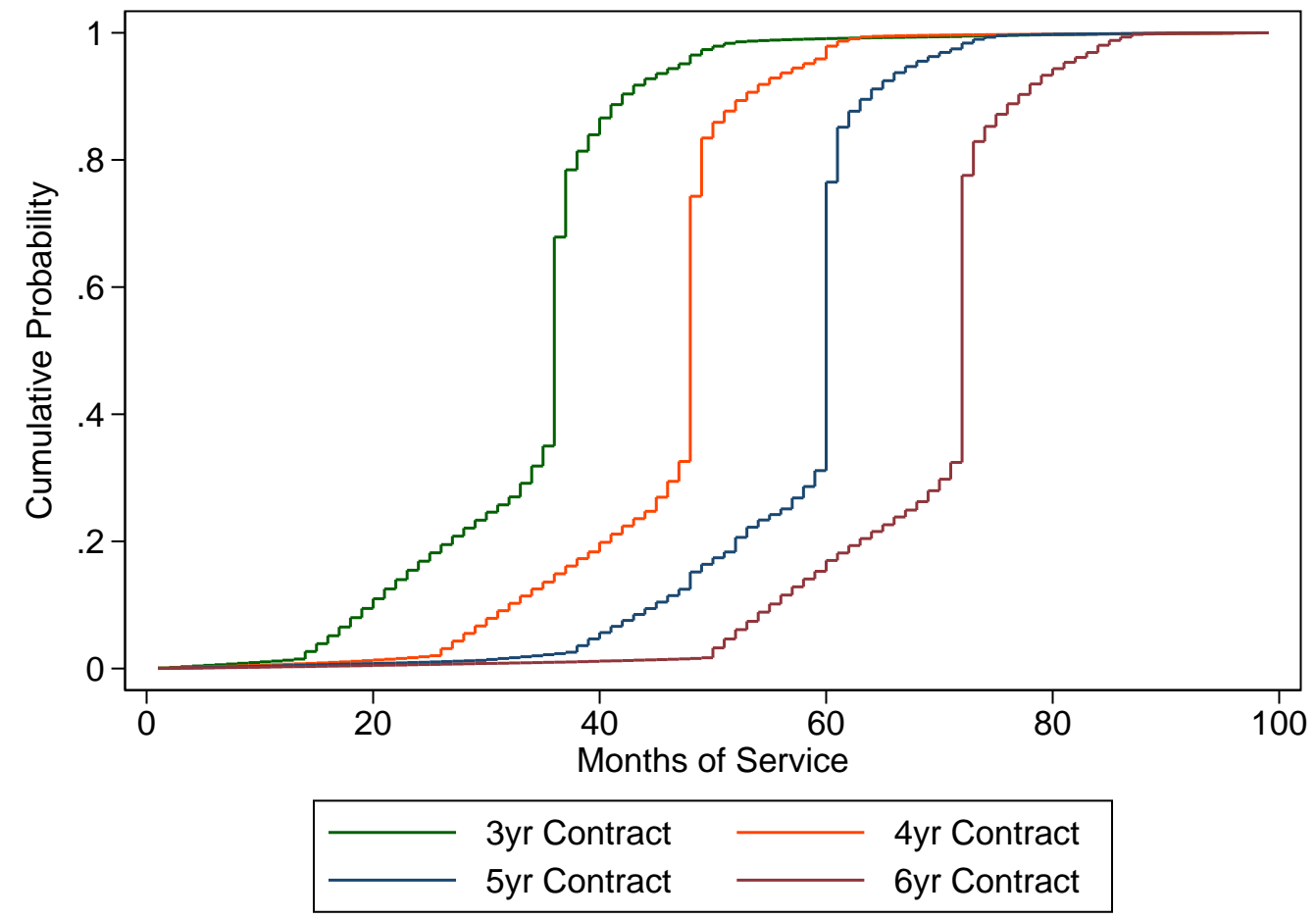

